\title{
OTTOMAN NAVAL WARS (1454-1918): (HISTORICAL STUDY)
}

\author{
Sahira Hussein MAHMOUD ${ }^{1}$
}

\section{Istanbul / Türkiye \\ p. 557-576}

Received: $15 / 11 / 2021$

Accepted: 06/12/2021

Published: 01/01/2022

This article has been scanned I iThenticat No plagiarism detected

\begin{abstract}
:
Most researchers focus on the land wars of the conflicting countries in ancient, contemporary, or modern history, which gives naval battles and their effects a second role in the causes of victory or defeat. Ottoman naval power and its battles are no exception. Through my study of most of the Ottoman wars in the ancient Ottoman and modern Turkish sources, I found that the impact of naval warfare is no less important than land wars, although they were not the direct causes of victory or defeat. Therefore, my research came to show the naval battles of the Ottoman Empire and to shed light on their causes and consequences.
\end{abstract}

Key words: Ottoman Empire, Ottoman Wars, Ottoman Navals This Humble Research Includes An Introduction, Two Axes.

http://dx.doi.org/10.47832/2717-8293.15.39

Dr. , Basra University, Iraq, saheraedu@ yahoo.com 


\section{حروب البحرية العثمانية (1454- 1918)}

(دراسة تأريخية)

\section{ساهرة حسين محمود 2}

الملخص:

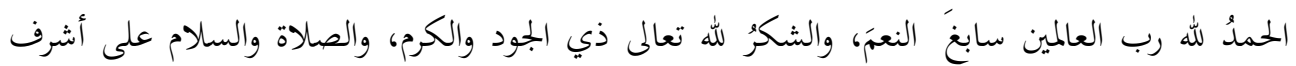

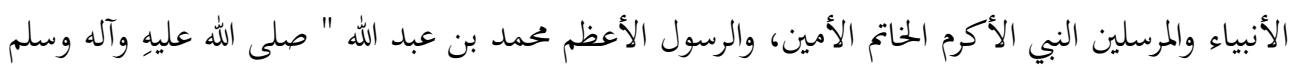

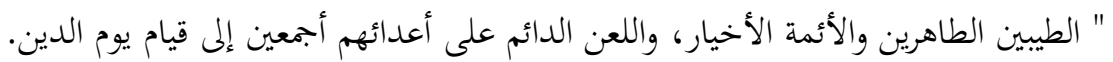
يركز أغلب الباحثين على الحروب البرية العائدة للدول المتنازعة في التأريخ القديم أو المعاصر أو الحديثين

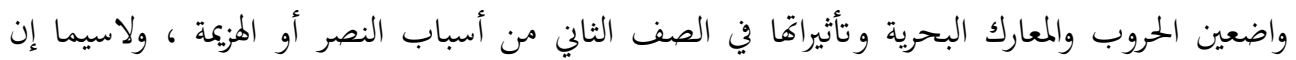

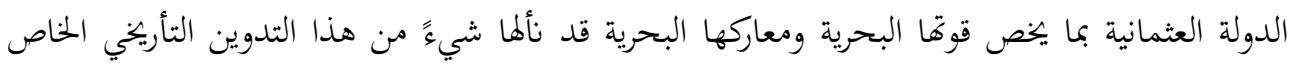
هذذا لموضوع، ومن خلال دراستي لاغلب الحروب العثمانية في المصادر العثمانية القديمة والمصادر التركية

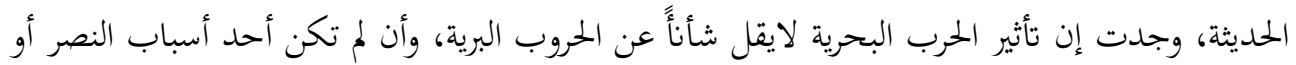
الهزيمة. فجاء بكثي هذا لأظهار المعارك البحرية للدولة العثمانية وتسليط الضوء على الأسباب و النتائج

الخناصة بما.

الكلمات المفتاحية: الدولة العثمانية، الحروب العثمانية، البحرية العثمانية .

كانت البحار مهمة للغاية في جميع جوانب تأريخ البشرية، تمامًاً كما هي اليوم، و لطالما أعتبرت الدول البرية أن الإبحار في

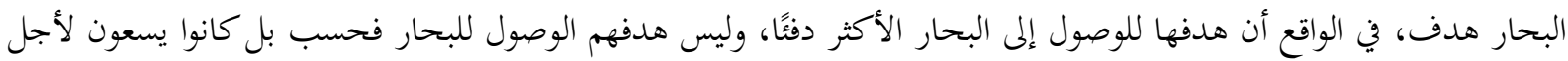

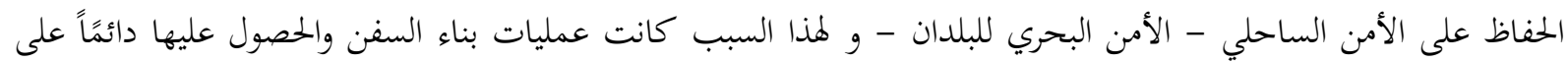

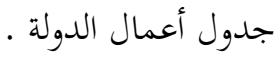

منذُ اللحظة التي بدأ فيها الأتراك الاستقرار في أراضي الأناضول المحاطة بالبحار من ثلاث جهات ، شعروا بالحاجة إلى التحول إلى البحر وبدأت عملية تطوير البحرية العثمانية في تأريخ الأنشطة البحرية التركية، عند إلقاء نظرة على المعالم الهامة سيساعدنا على فهم عمليات التنمية الطبيعية للبحر عبر التأريخ، وتفاعل التطورات الدورية مع الملاحة البحرية للأتراك، مما يوجه هذا التفاعل التنبؤات بالأنشطة والتفاعلات البحرية المستقبلية. و في هذه البحث الذي يهدف إلى إلى التحقيق في أوائل لقاءات الحربية للأتراك مع البحر في التأريخ، وتأثيره على الأنشطة البحرية الحربية إلى جانب عملية التطور التأريخي والسياسي ومراحل التنمية التي تتزامن مع عمر الدولة العثمانية.

أن المنظمات والسفن البحرية التابعة للعثمانيين، الذين كان لديهم تفوق خطير في البحار، تستحق أيضًا أهتمامًا خاصًا في

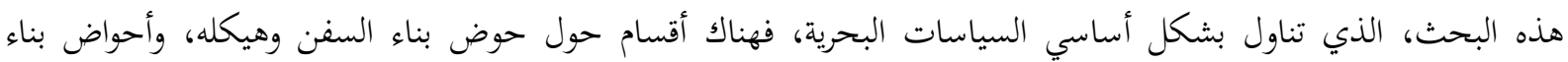
السفن في مناطق جغرافية أخرى من الإمبراطورية، والضباط العاملون في حوض بناء السفن والبحرية، والسفن المستخدمة في 
البحرية بالإضافة إلى ذلك، يجذب الأنتباه إلى قصص الحياة والأنشطة البحرية للبحارة الرواد، التي أدت إلى تغييرات وتحولات كبيرة في المجال البحري.

عندما أراد الأتراك أن يجعلون الأناضول وطنهم، شعروا بضرورة تنفيذ إستراتيجية جديدة، إذ أدركوا بما أن الأناضول محاطة

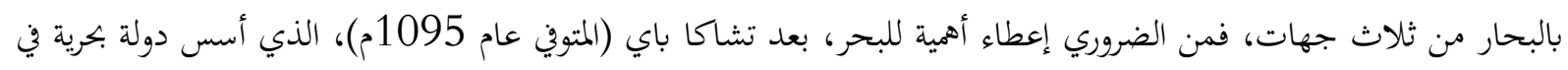
غرب الأناضول، فبدأ الأتراك في بناء أحواض بناء السفن ومقاعدها، وبناء القوات البحرية خلال حكم دولة تركيا الحديثة. 


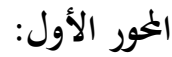

حروب البحرية العثمانية (1454 - 1700م) (170)

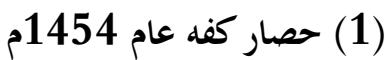

كان حصار (كفه Kefe) أحد العمليات العسكرية للإمبراطورية العثمانية وخانية القرم، اللتين تحالفتا في عام

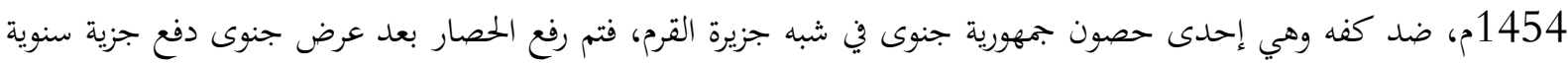

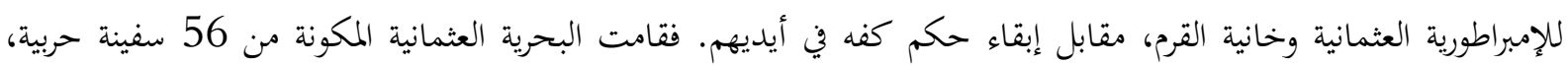

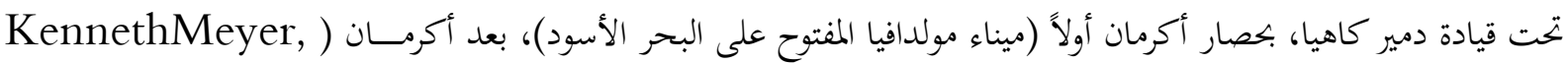

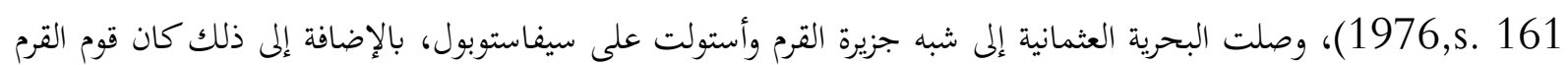

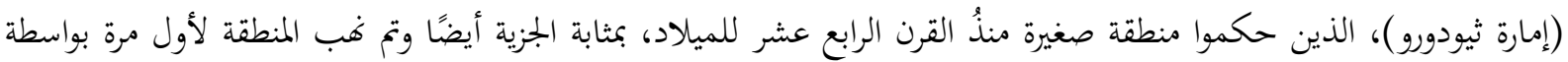
أسطول تركي أرسله السلطان مراد الثاني (1446- 1451م)، في عام 1446 م (İdris Bostan,2000,s.37).

\section{(2) (2) حصار أماسرا عام 1460م}

كان حصار أماسرا هو العملية البرية والبحرية التي أسفرت عن قيام الجيش العثماني بقيادة الفاتح سلطان محمد الثاني

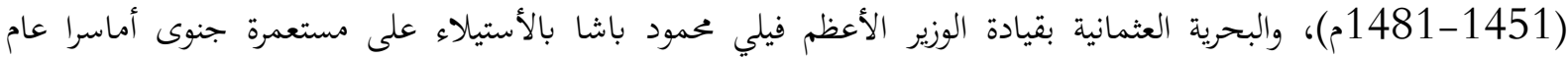

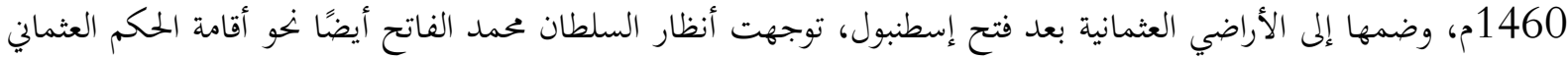

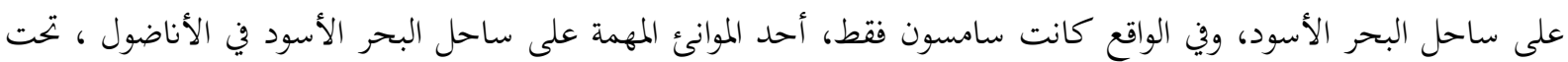

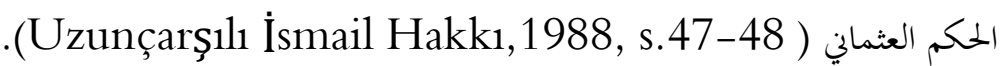

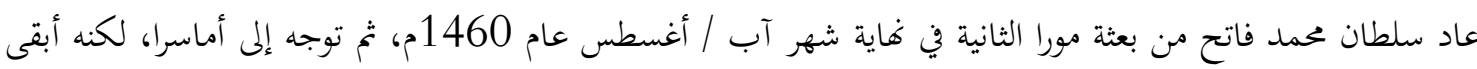

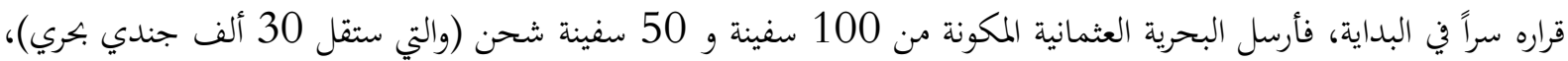

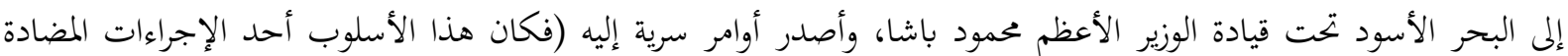

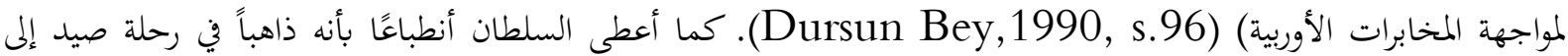

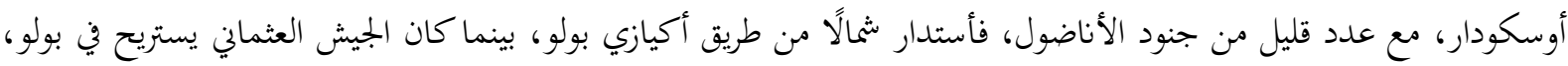

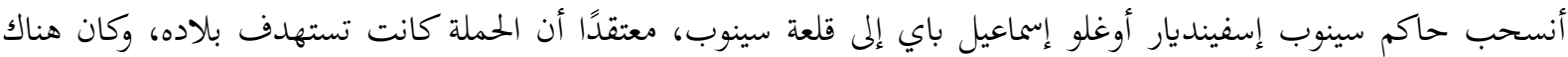

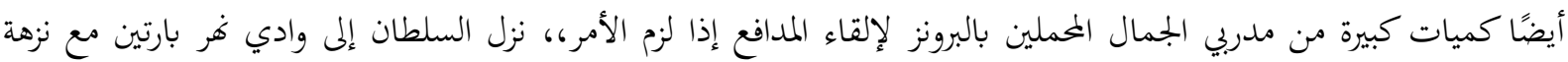

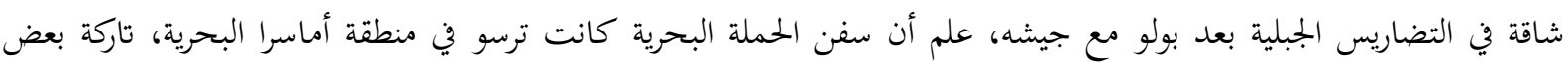

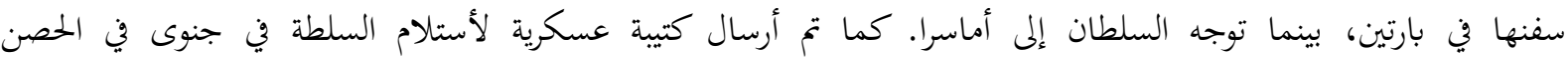

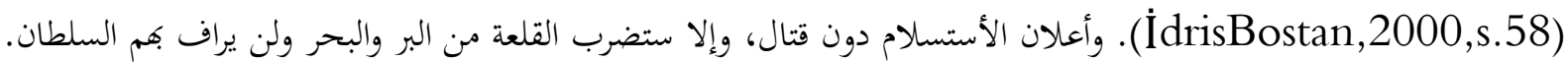

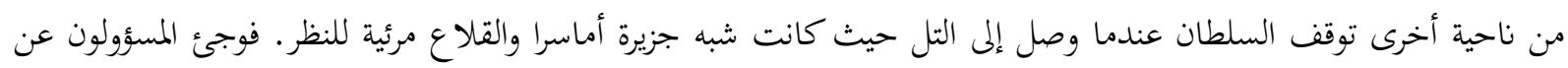

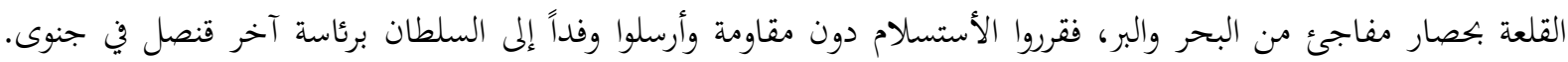

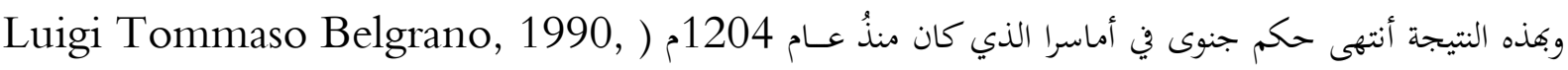
.(s.19, 20 


\section{(3) معركة الريس براق البحرية عام 1499م}

تُعرف أيضًا بإسم معركة بحر سابينزا أو معركة بحر زونشيو أو معركة بحر إنيباتي الأولى أو معركة جزيرة بوراك ريس البحرية.

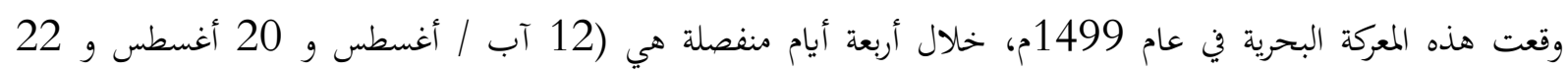

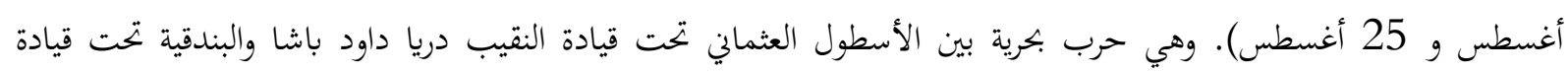
النقيب العام أنطونيو جريماني في عهد السلطان بايزيد الثاني (1481-1512م)، فقد كاندية الندانت معركة بحرية أنتهت بأنتصار تكتيكي

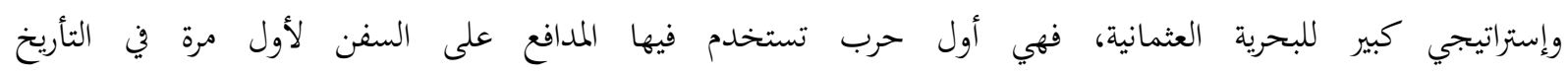
(GökhanAtmaca ve Doğan Tanriverdi ,2016 ,s.57.)

دخلت سفن الأسطولين في قتال متلاحم، وفقًاً لمصادر الفينيسية، فهاجمت سفنها السفن العثمانية ، بشجاعة كبيرة في

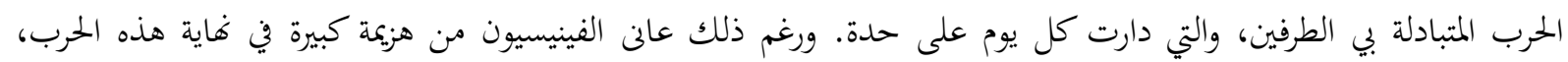

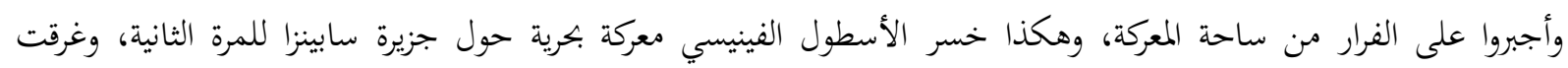

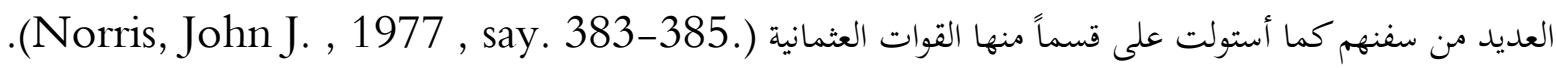

\section{(4) معرب ديو البحرية 3 شباط / فبراير عام 1509م}

كانت معركة ديو والمعروفة أيضًا بإسم معركة شاول الثانية، وهي معركة بحرية وقعت في 3 شباط / فبراير 1509م، قبالة

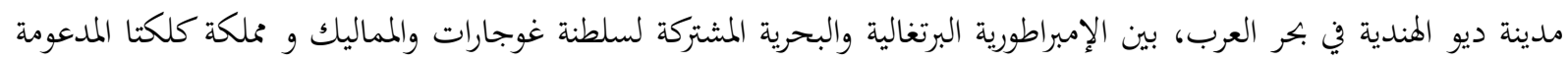

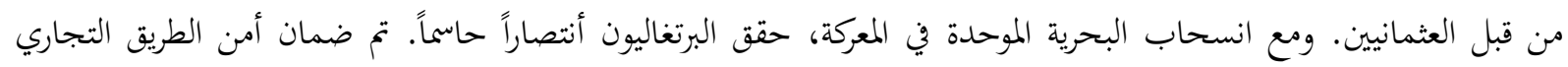

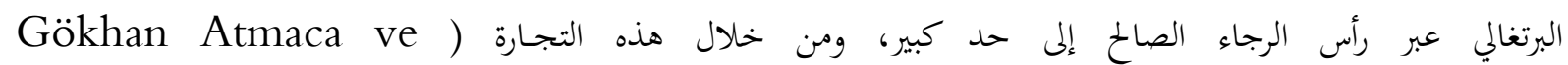
(DoğanTanriverdi ,2016,s72. فاصلة من الناحية الإستراتيجية إذ اهت سيطرة المسلمين على خطوط التجارة البحرية مع آسيا وبدء السيطرة الأوروبية على المسرح

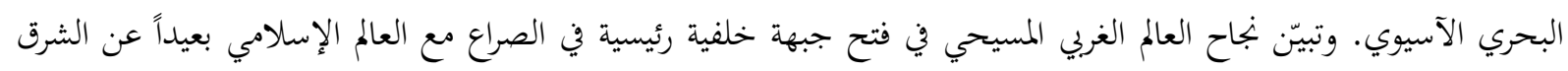

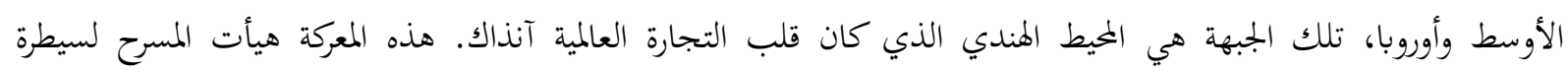

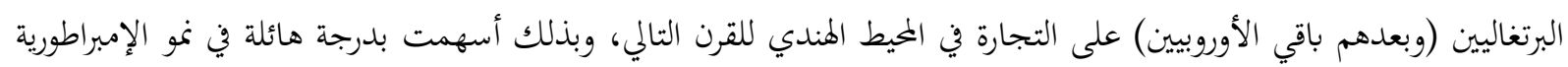
البرتغالية (ومن بعدها الإمبراطورية البريطانية) (233- Rogers, Clifford J. Readings 1995, pp. 299).

\section{(5) حصار جدّة 19 نيسان / أبريل عام 1517م}

تصدت جدة لحصار سفن البحرية البرتغالية - الهندية عليها في عام 1517م، من قبل البحرية والحامية المملوكية المدعومة

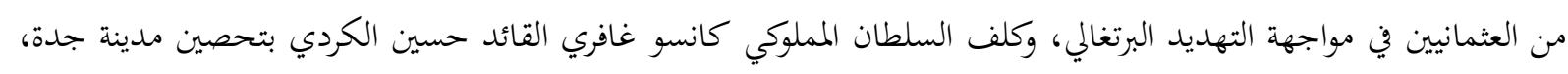

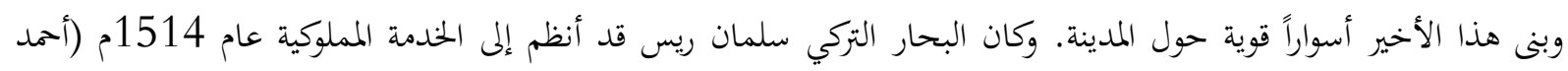

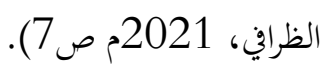

حاولت سفن البحرية البرتغالية الأستيلاء على مدينة عدن في عام 1513م، وأيضاً في عام 1517م، لكنها فشلت في

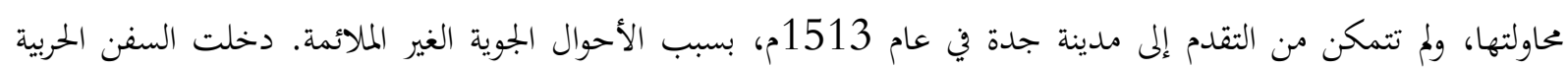

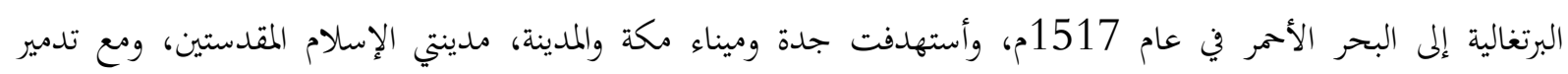

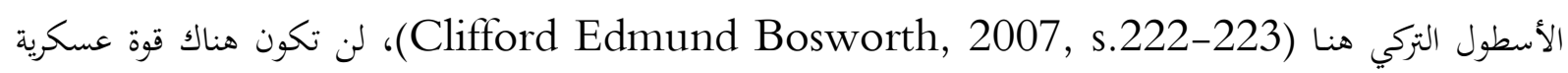
متبقية في البحر الأحمر يمكن أن تمنع السفن البرتغالية، التي شرعت في عملية أختراق لم تستطع أن تكون فعالة ضد نيران مدفعية

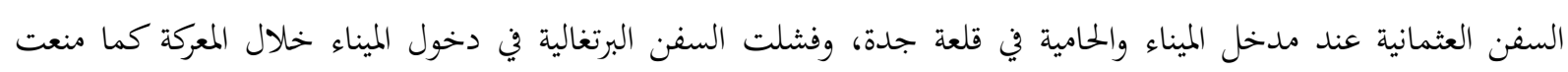


المدافع العثمانية من نوع باكالوشكا، التي يبلغ طولا 550 و 660 سم والقادرة على رمي قذائف المدفعية ما يقرب من 5 رئل كيلوغرامات السفن البرتغالية من الأقتراب أكثر من اللأزم من القلعـة (Ahmet Kavas, 2001, s 111)

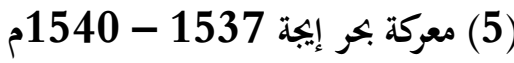

كان المدف الأول للبحرية العثمانية هو جزيرة سيها جنوب البيلوبونيز، وأستولت البحرية على قلعة باليو هورا وأستعبدت

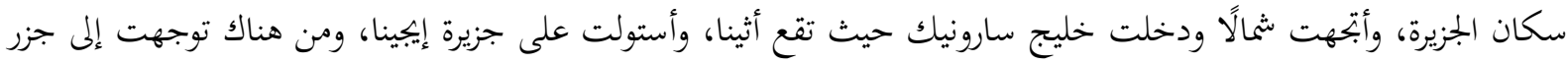

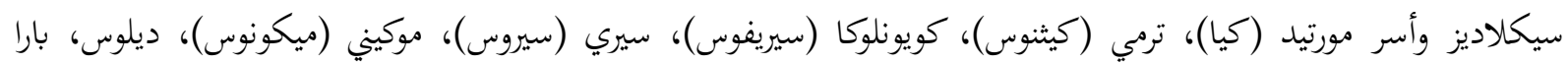

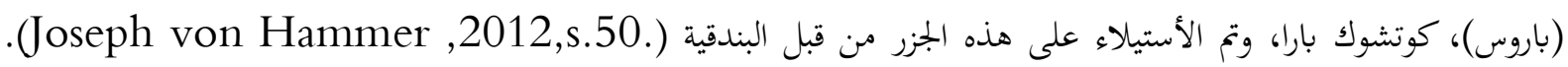

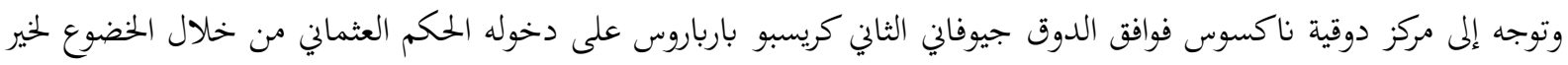

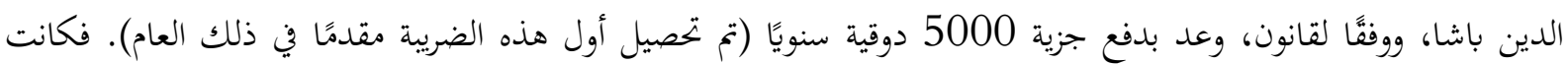

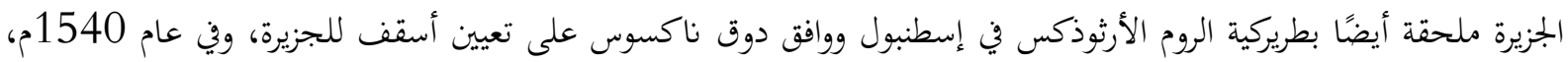

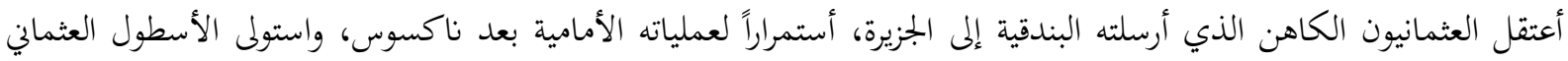

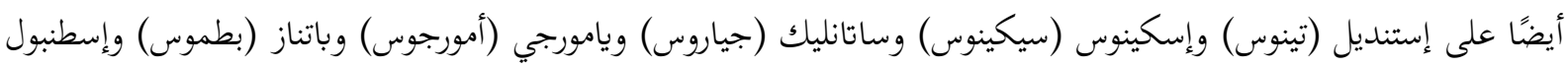

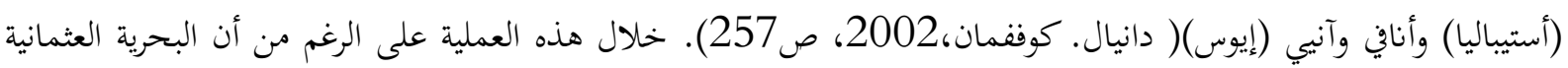

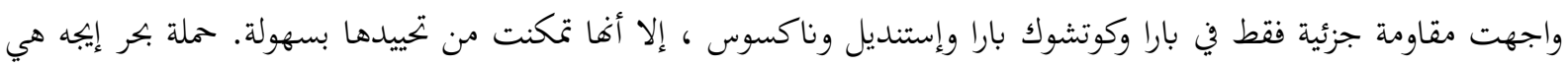

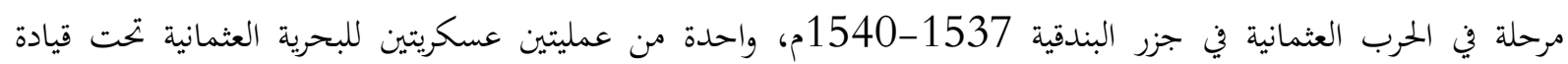

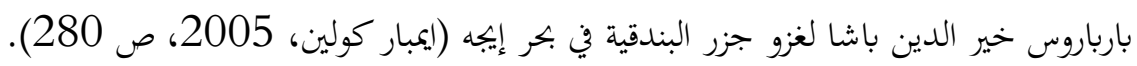

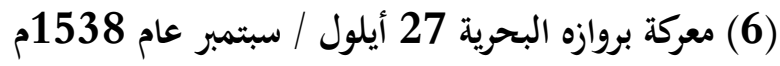

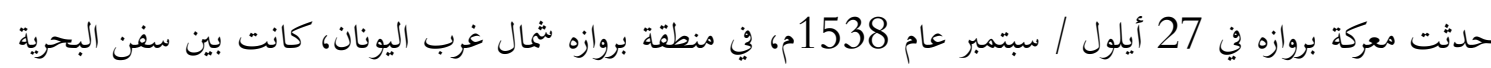

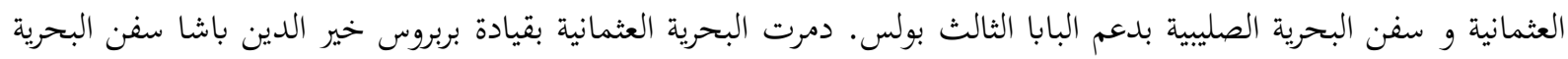

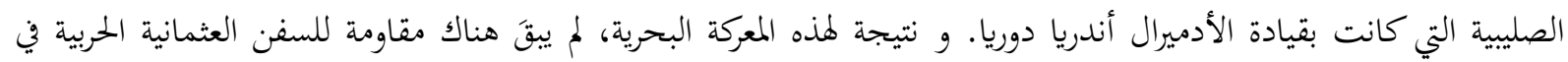

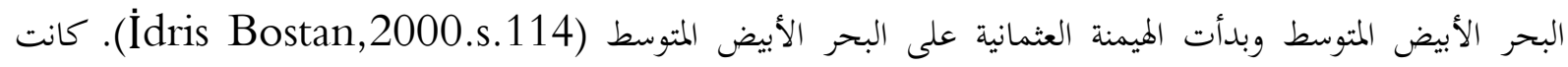

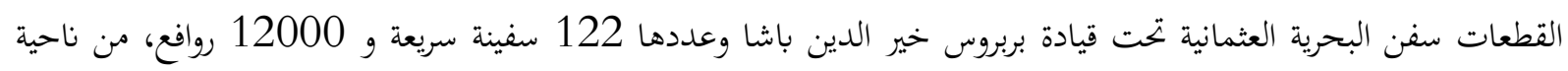

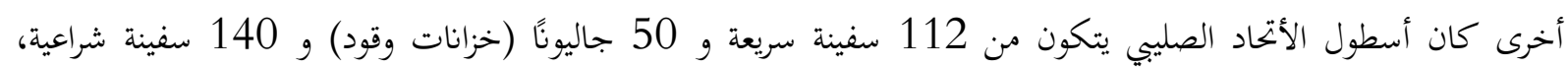

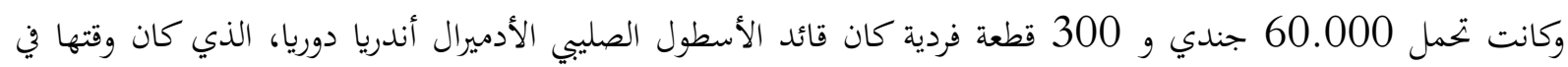

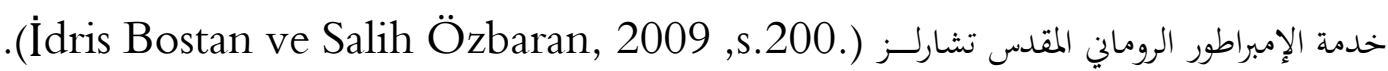

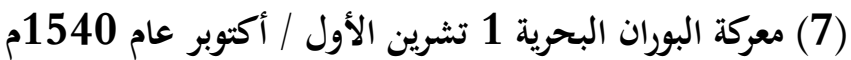

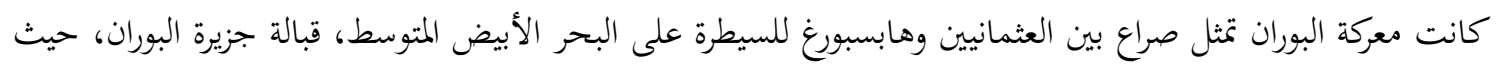

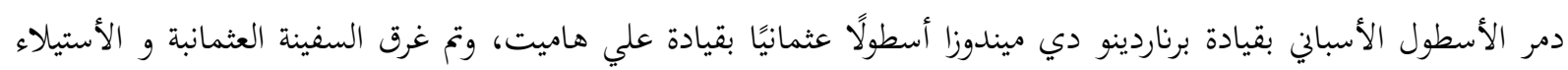

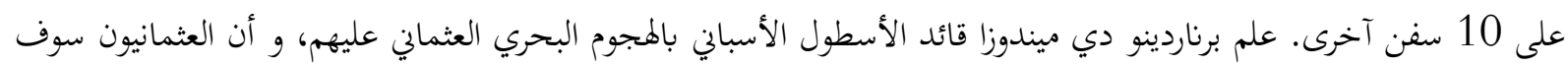

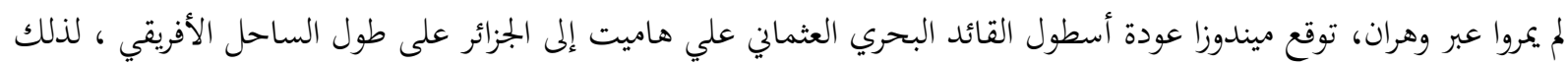

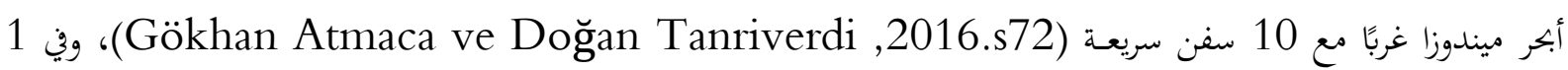

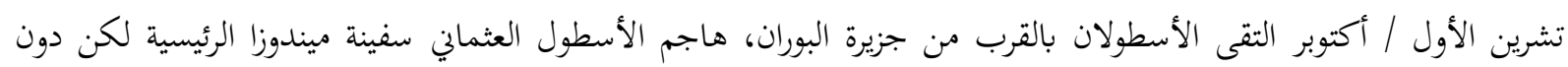

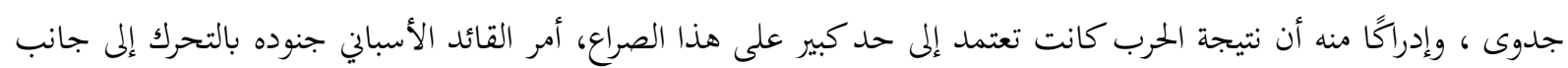


واحد، ورفع الجانب الآخر ليكون بمثابة مجموعة ضد نيران السفن العثمانية. ثم صعدت قوات ميندوزا إلى السفن العثمانية

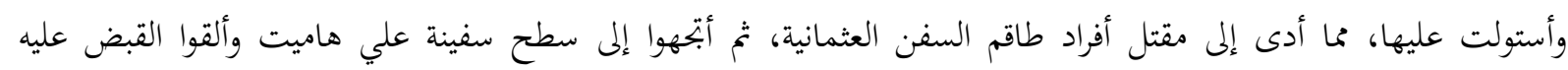
.(İdris Bostan, 2000.s 84)

وكانت من نتائج هذه المعركة الأستيلاء على عشرة من بين ستة عشر سفينة عثمانية، وغرق سفينة واحدة، كما تم قُتل

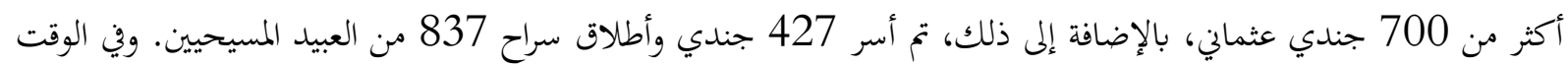

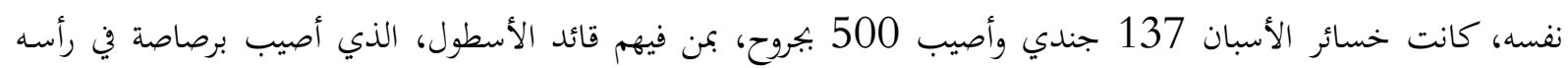
.(İdris Bostan ve Salih Özbaran, 2009.s.150)

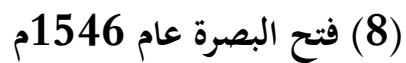

فتحت الإمبراطورية العثمانية البصرة في عام 1546م، منعاً من وقوعها في أيدي البرتغاليين. كلفت الدولة العثمانية والي

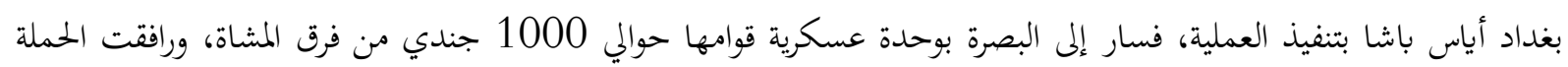
120 سفينة صغيرة تحمل مستلزمات الحصار و ذخيرة المدافع. (Abdurrahman Sağırl1, 2000, s. 44). على الرغم من أن أياس باشا بعث برسالة إلى الشيخ يميى على بوابات البصرة وطلب منه تسليم المدينة، فأرسل الشيخ

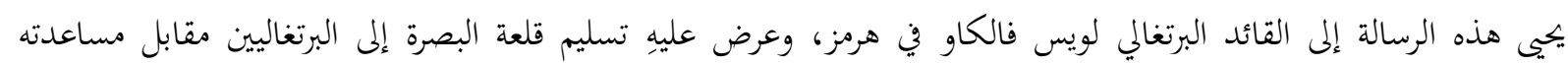
للتصدي للعثمانيين. وفي 30 تشرين الثاني / نوفمبر عام 1546م، أعرائ إعربت القيادة البرتغالية في هرمز عن وجهة نظرها للقائد العام

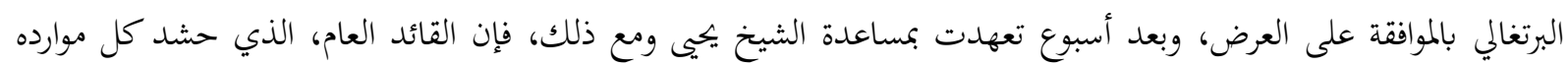

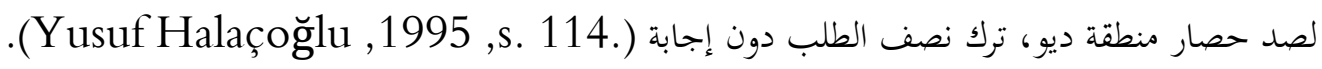
أسقطت الكتيبة العثمانية في وقت قصير قلعة زكية التي كانت تعتبر مفتاح البصرة، وكذلك منطقة الكرمة التي تقع على ضفاف غري دجلة و الفرات وشط العرب، إلا أها لم تستطع مقاومة القوة النارية الفعالة للجيش العثماني، وقد أكتمل إحتلال

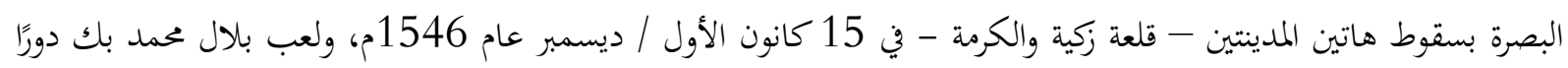

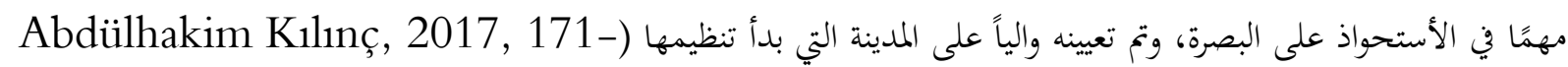

\section{(9) فتح عدن 26 شباط / فبراير عام 1548م}

أستعادة الإمبراطورية العثمانية مدينة عدن في 26 شباط / فبراير عام 1548م، التي سقطت في أيدي شيوخ عرب محليين

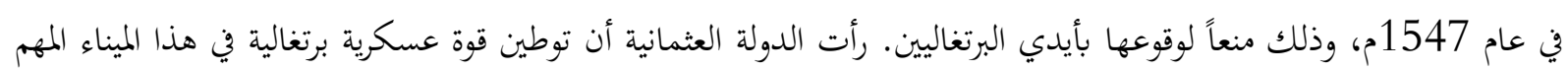

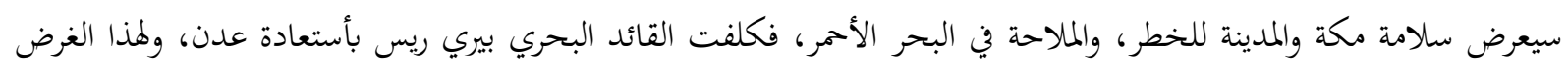

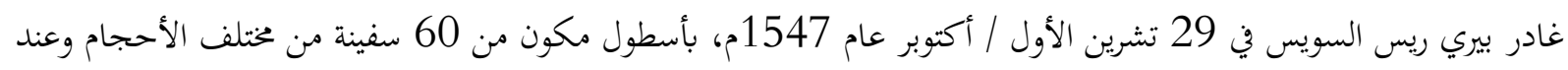

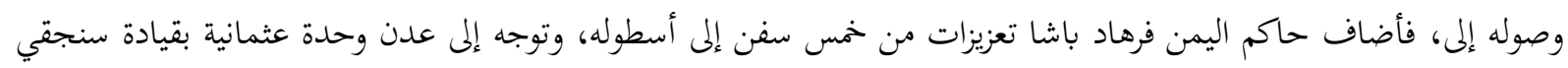
قاسم بك عدن فحاصرتما براً (Ertuğrul Önlap,2000,s.7).

وعند وصول الأسطول العثماني بالقرب من عدن في 15 تشرين الثاني / نوفمبر عام 1547م، هاجم علي بن سليمان

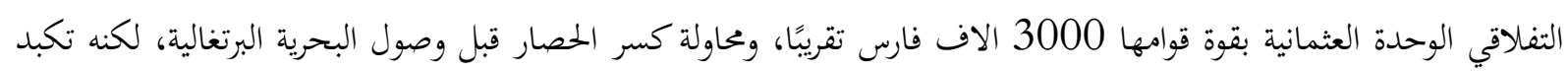

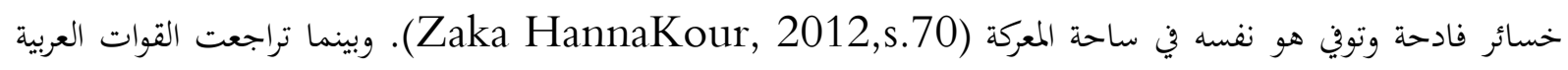

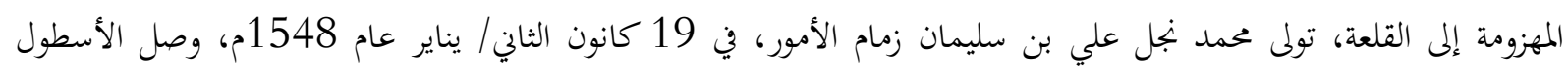

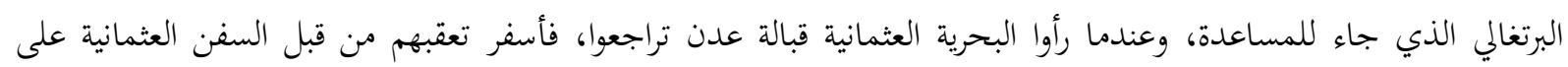


Aksaray, ) السيطرة عليها في ميناء زيلا الواقع قبالة السواحل الصومالية و الأستيلاء على 120 سفينة برتغالية و حرق بعضها (Y. Bülent, 2007,s.45.

عقب الأنتصار، حُصرت مدينة عدن من البحر أيضًا، ووضعت المدافع على الشاطئ وأضرمت النيران في الجدران، وفي

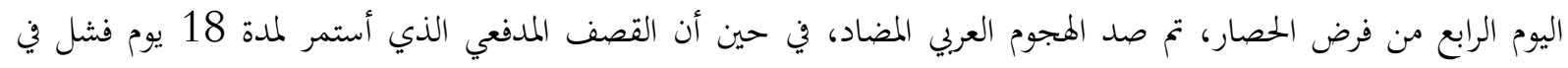

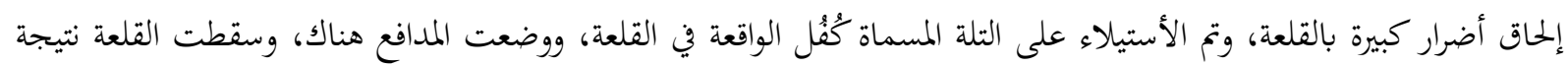

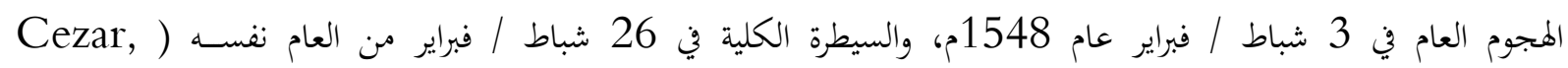
.(Mustafa, Mufassal, 1958,s.125.

\section{(10) معركة بونزا البحرية 5 آب / أغسطس عام 1552م}

معركة بونزا معركة بحرية وقعت قبالة جزيرة بونزا الإيطالية في العام 1552م، تقاتل فيها الأسطولين العثماني بقيادة درغوث

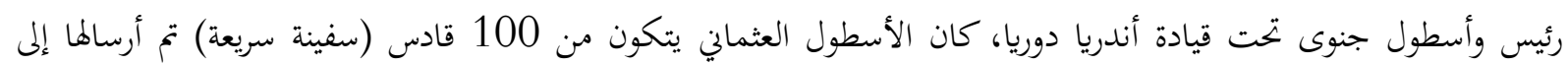

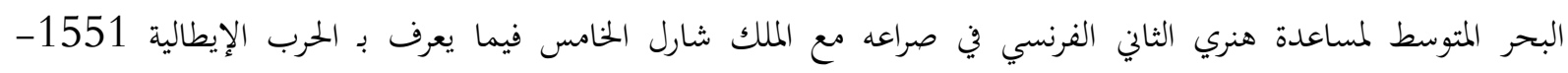

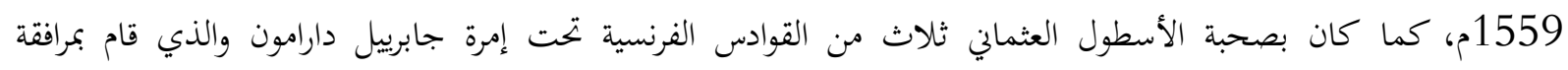

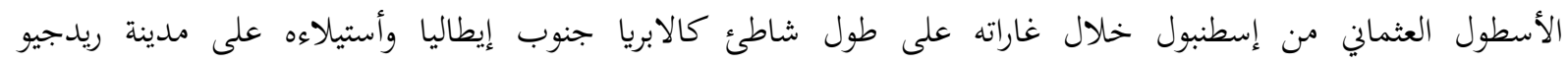

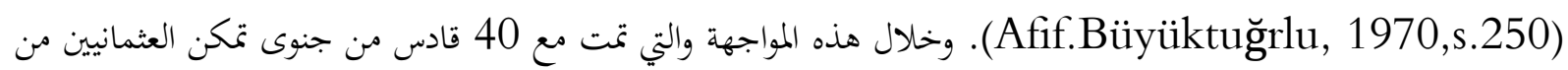

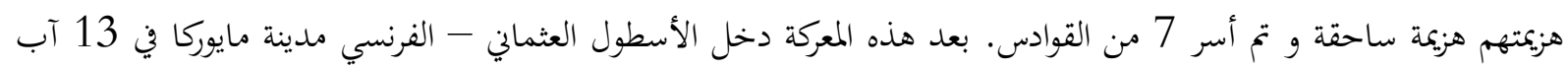

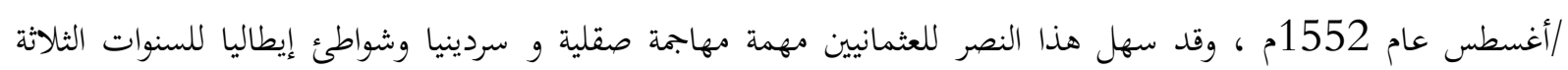
القادمة (Halil. İnalc1k , 2004,s.82).

(11) معركة هرمز البحرية 9-25 آب /أغسطس1554م

وقعت معركة هرمز في 9 آب / أغسطس عام 1554م، في مضيق هرمز بين البحرية الحربية العثمانية بقيادة سيدي علي

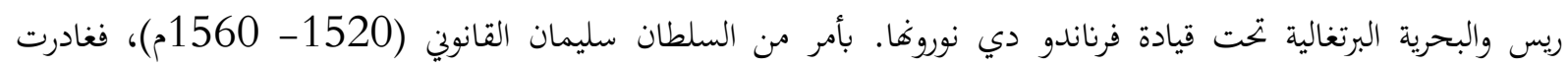

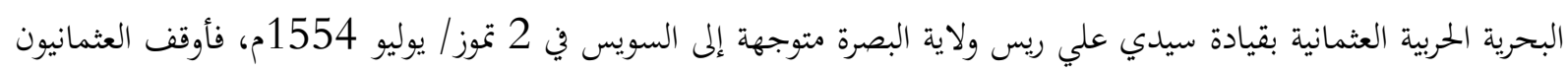

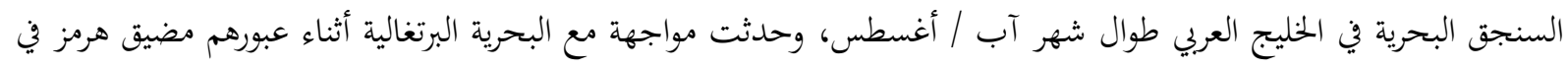

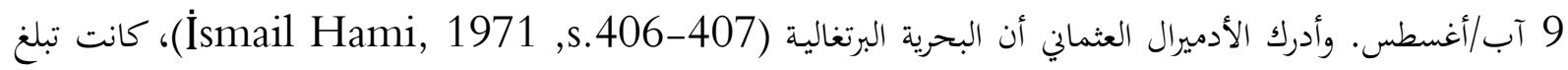

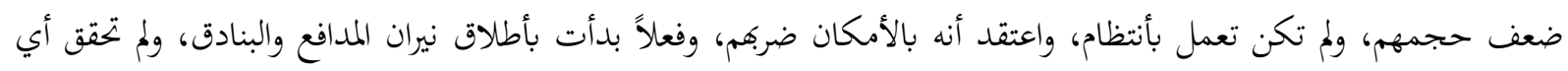
نتائج تذكر في المعركة، والتي أستمرت حتى الفجر، فقدت لندمن البحرية البرتغالية العديد من البحارة وأغرقت سفينة شراعية فوقها. عiئذ بدأت تتراجع بشكل غير متساوي بأبتحاه جزيرة هرمز (-) 
غادرت البحرية العثمانية، التي كانت في الحملة الهندية الرابعة في صيف عام 1554م، الخنليج العربي بعد معركة هرمز ووصلت إلى ميناء صحار في عمان، بعد مغادرة الميناء والأبحار إلى السويس ، وواجهت البحتية البحرية العثمانية البحرية الحربية البرتغالية التي حاصرت مسقط يوم السبت 25 آب /أغسطس عام 1554 م(Ahmet Güleryüz , 2004,s.250). اعتقدت البحرية البرتغالية بقيادة فرناندو دي نوروغا، والتي تتكون من 34 سفينة ولديها العديد من الجنود، وأفها ستعطل

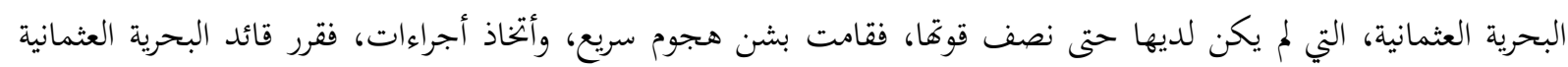

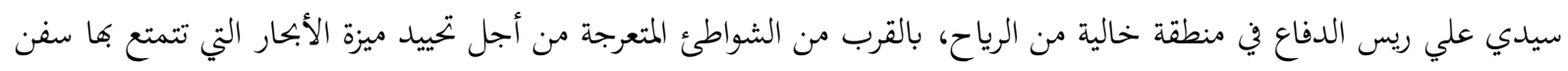

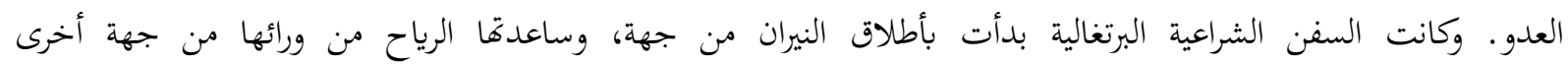

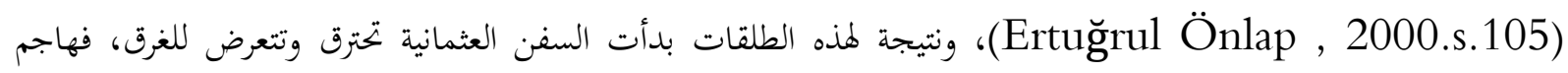
سيدي علي ريس 14 قودساً وركب سفنهم قبل أن تتمكن القوادس البرتغالية من اللحاق بها. وحدثت المواجهة بين الجانبين،

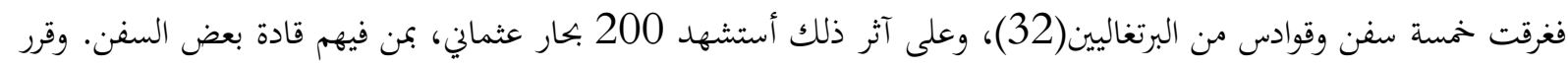

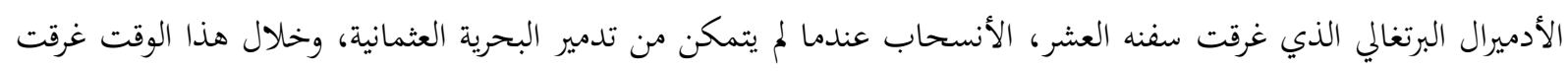

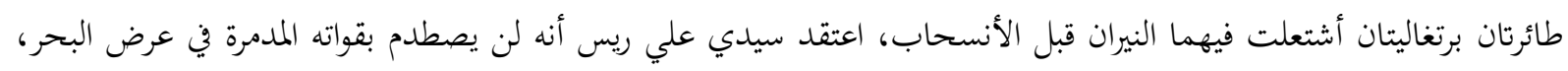

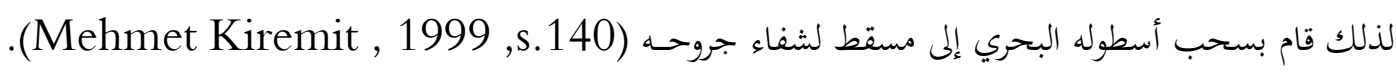

1560 13) معركة جربة البحرية

حدثت معركة جربة بين البحرية العثمانية بقيادة الأدميرال بيالي باشا والبحرية الصليبية بقيادة القوات الإسبانية في أيار /

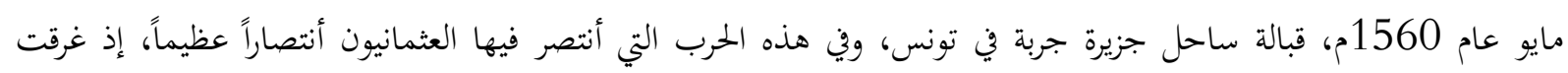

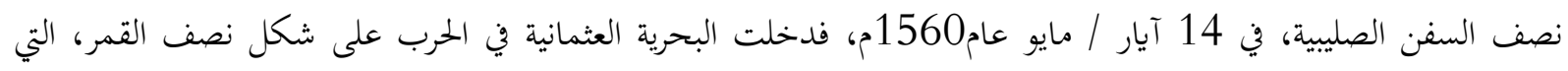

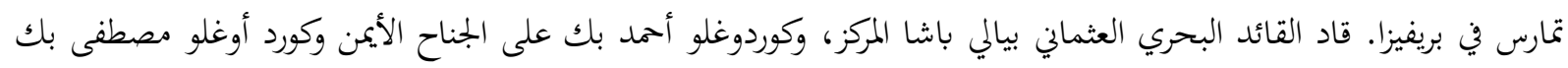

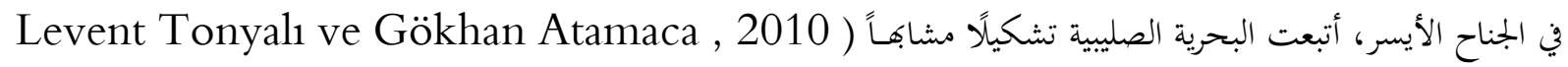

فبدأت هذه المعركة بالمدفعية، ولاحظ بيالي باشا علامات الذعر والهزيمة في الأسطول الصلبي نتيجة الضربات الدقيقة

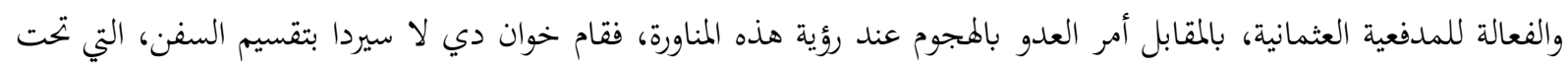

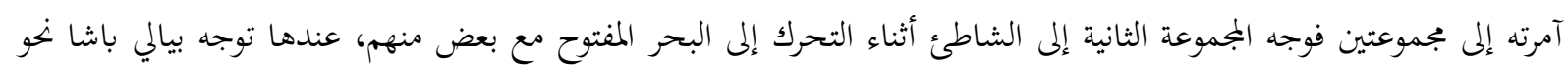

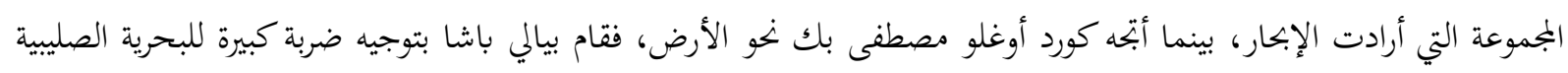

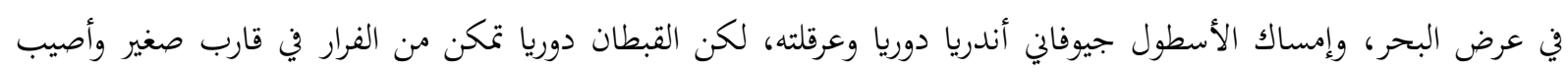

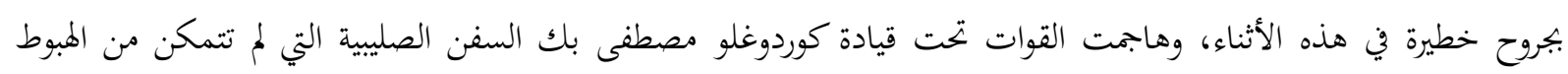

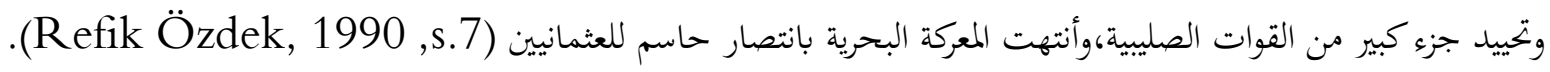

\section{14) حصار مالطا عام}

حصار مالطا أو حملة مالطا هي عملية حصار على جزيرة مالطا من قبل قوات الدولة العثمانية في عام 1565م، ودفاع

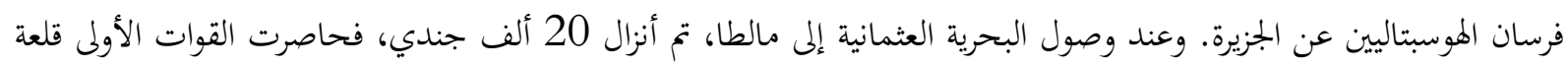

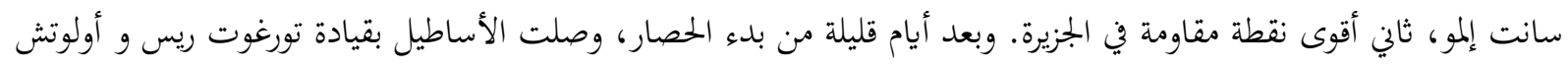

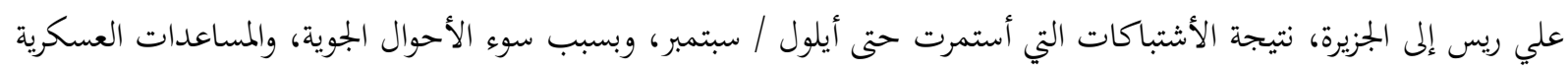


المتوقعة أيصالها للعدو من صقلية عبر شمال الجزيرة، قرر القائد العام كيزيلمدلي مصطفى باشا رفع الحصار والأنسحاب في 11 أيلول/ سبتمبر عام 1565م، ورفع الحصار بالكامل (Levent Tonyal1 ve Gökhan Atamaca,2010.s.70).

\section{(15) فتح قبرص 16 آيار / مايو عام 1570- 1 آب/ أغسطس 1571م}

الحرب العثمانية - الفينيسية أو حملة قبرص - هي الحرب الرابعة بين العثمانيين والبندقية. وقد كانت بين الدولة العثمانية

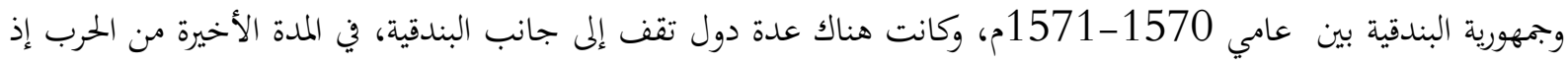

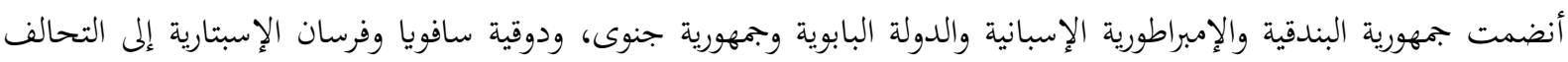
المقدس، الذي تم تشكيله بمبادرة من البابا بيوس الخامس(Refik Özdek , 2010,s.45). وكانت أهم عملية عسكرية لحكومة السلطان العثماني سليم الثاني (1566 -1574م)، أن التوتر الذي بدأ مع محاولة حصار مالطا في عهد السلطان سليمان الأول (1520-1566م)، وأستمر مع الرحلة الأستكشافية إلى قبرص الواقعة تحت سيطرة جمهورية البندقية. وبعد

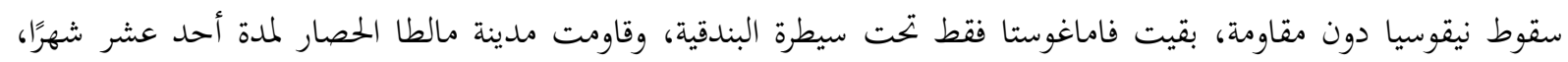

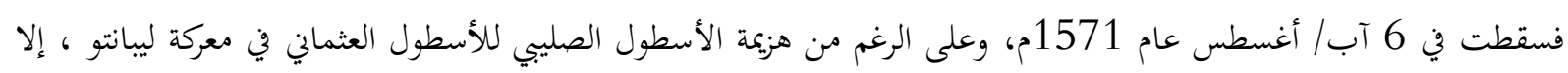

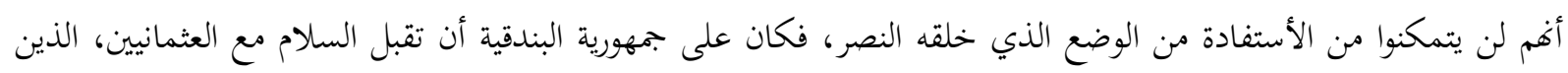
كانوا يقومون بناء أسطولم البحري بسرعة (Çevikel, Nuri , 2006, s. 102).

1571م (16) معركة ليبانتو البحرية عام

حدثت معركة ليبانتو البحرية بين الدولة العثمانية والأساطيل الصليبية على برزخ كورنث، بالقرب من ليبانتو، في 7 تشرين

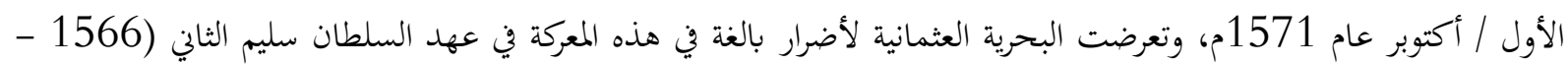

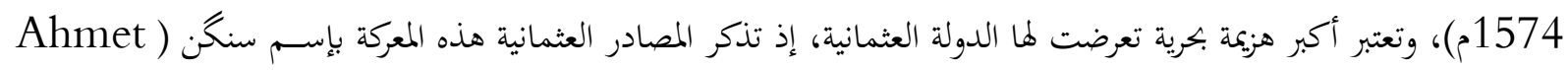

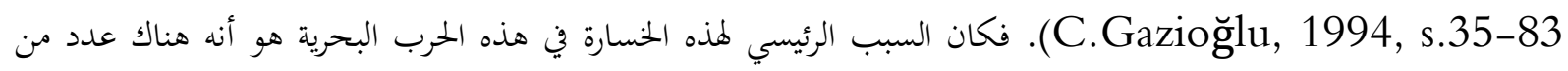

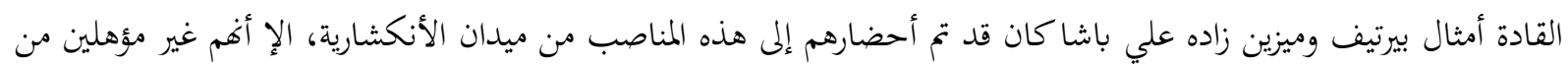

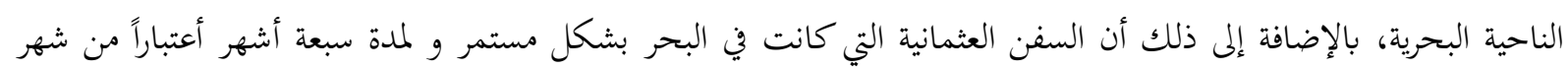

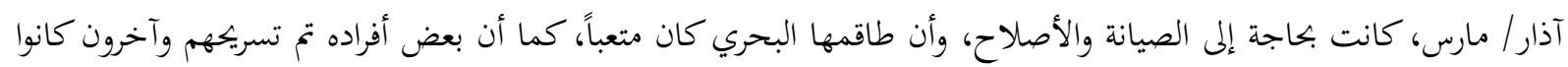
مجازين، فتم تعزيز الطاقم البحري من قبل الفرسان من غير البحارة (Günen Çoşkun , 1995 , s.562).

\section{(17) معركة وادي سيل البحرية عام 1578م}

معركة وادي سيل أو معركة وادي المعازين وهي معركة كانت بين قوات سلطان المغرب السعدي عبد الملك (1576 -

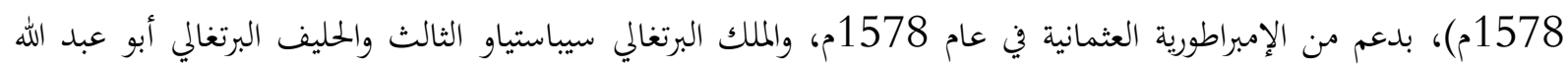

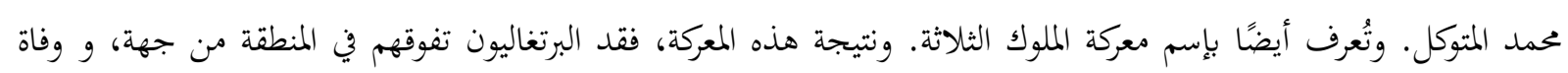

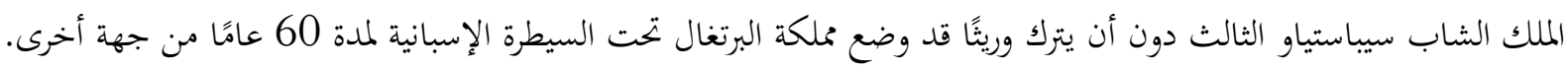

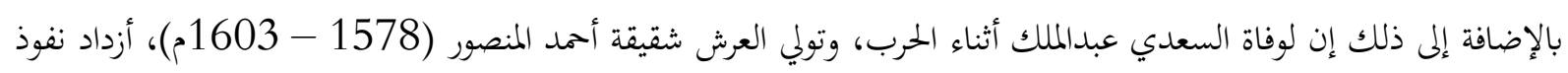
الإمبراطورية العثمانية على المغرب أكثـر (Nejat Tarakç1 , 2009,S.25).

(18) معركة مومباسا عام 1584 -1589م

وقعت معركة مومباسا في 5 آذار / مارس عام 1584م، في مدينة مومباسا، وهي مدينة ساحلية في دولة كينيا الحالية.

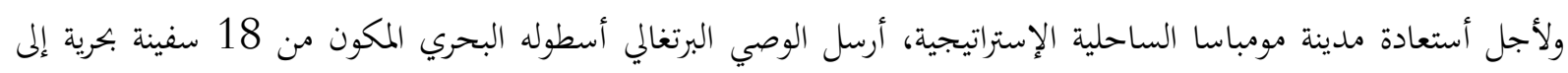

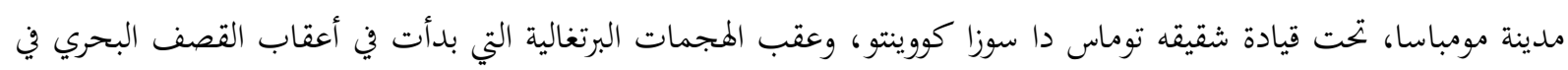


5 آذار / مارس عام 1589م، وتم خلال المواجهة بين الطرفين حرق السفن العثمانية، والأستيلاء على قلعة مومباسا، وُهزَم الأمير

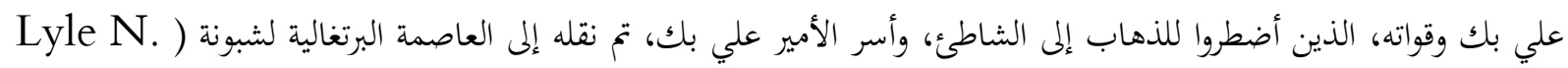
.(McAlister, 1984,p.p 125

\section{(19) معركة جهنم السوداء البحرية تموز/ يوليو عام 1609م}

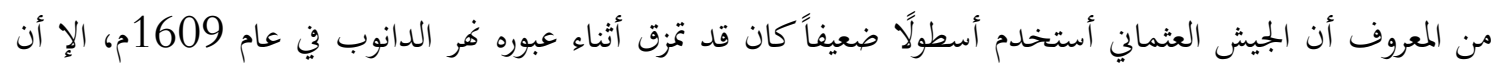

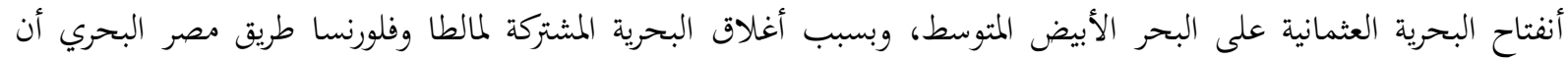

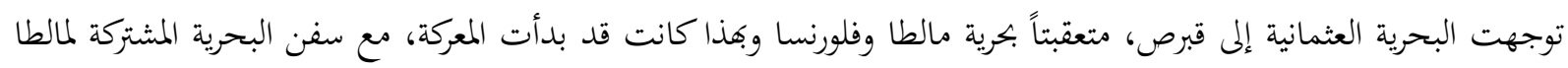

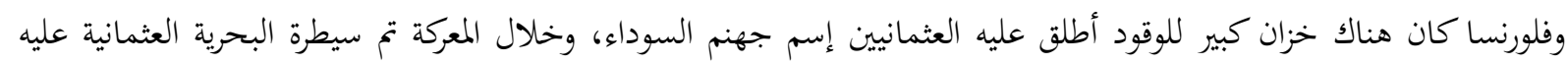

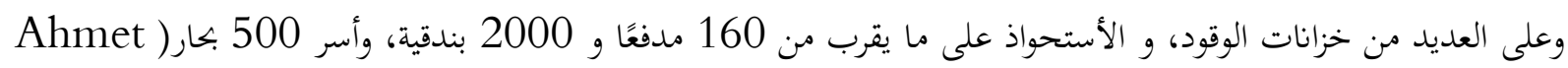

.(,Kavas , , 2005,s.170

\section{(20) معركة كيب جيلدونيا 14-16 تموز / يوليو عام 1616م}

كانت معركة كيب جيلدونيا قد وقعت بين الإمبراطورية الإسبانية والإمبراطورية العثمانية بين 14-16 تموز / يوليو عام

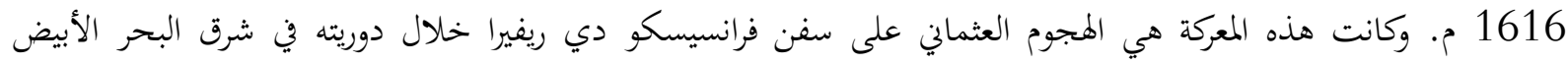

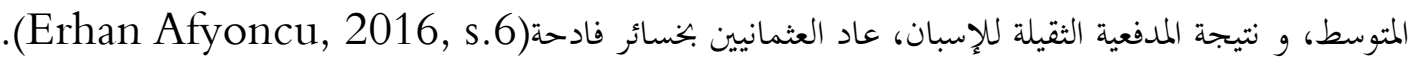

(21) معركة قارا هرمان البحرية عام 1625م

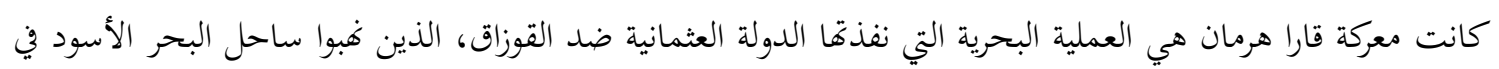

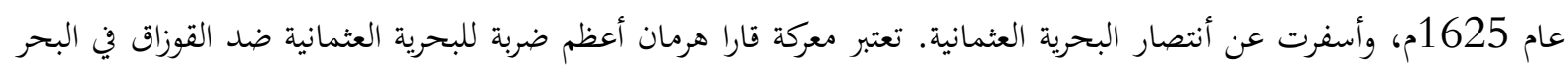

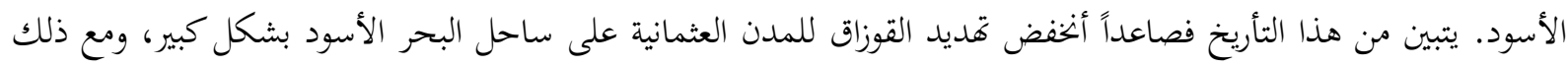

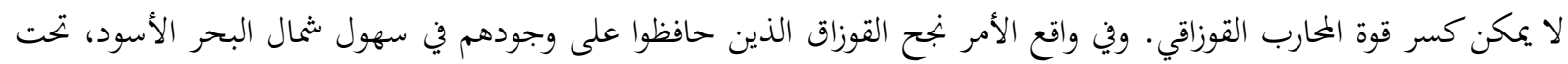

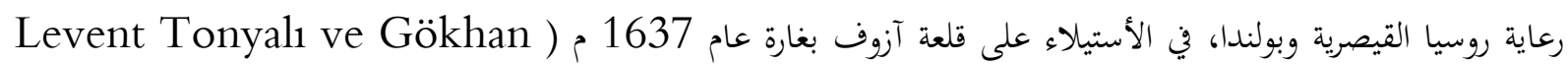
.(Atamaca, 2010, s.574

\section{(22) معارك جاناق قلعة البحرية عامي 1654 - 1669م}

كانت معركة الدردنيل البحرية الأولى التي خاضتها البحرية العثمانية تحت قيادة مراد باشا مع سفن جمهورية البندقية بقيادة إنيا

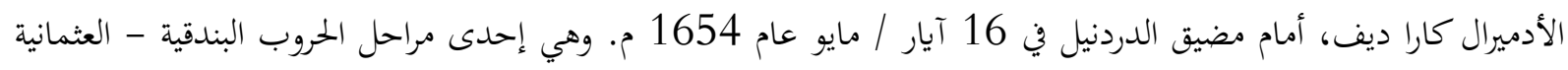

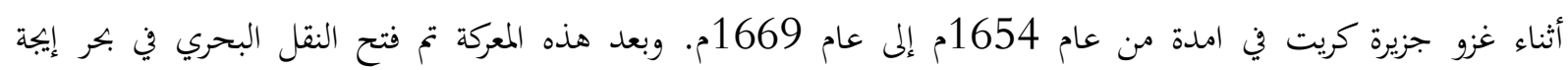

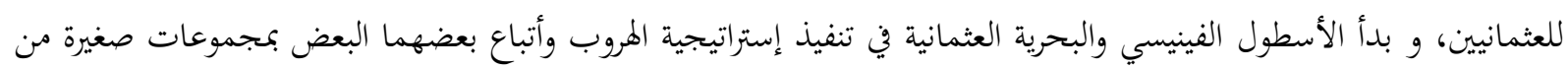

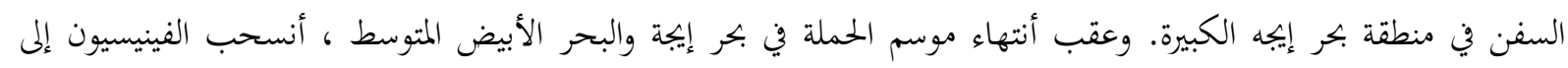

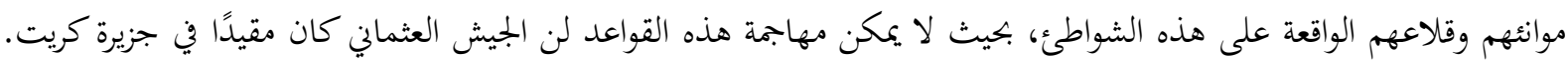

(Ahmet C.Gazioğlu, ,1994, s.245)

أما معركة الدردنيل البحرية الثانية بقيادة الأدميرال مصطفى باشا مع سفن البحرية لجمهورية البندقية أمام مضيق الدردنيل

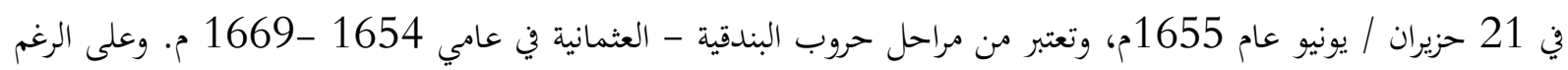

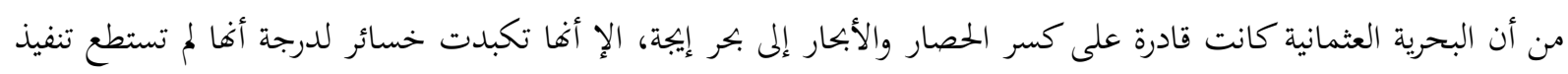


عملية حربية بحرية، على نطاق يمكن أن يغير الوضع في جزيرة كريت. الأ أن شجع هذا النجاح في الدردنيل البنادقة على أرسال أسطول أكبر إلى المنطقة بعد عام من هذه المعركة ( Levent Tonyalı ve Gökhan Atamaca, 2010,

معركة الدردنيل البحرية الثالثة، وهي المعركة البحرية للبحرية العثمانية بقيادة الأدميرال سري كنان باشا مع سفن البحرية

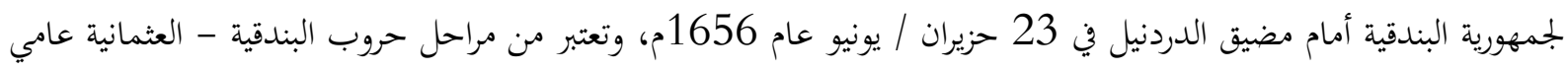

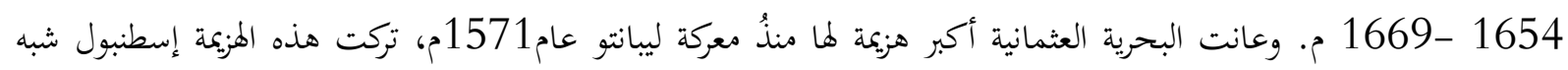
معزولة (Aktepe, M. Münir, 1994,s.375-376).

\section{7 (23) - (23) حصار ليمني عام}

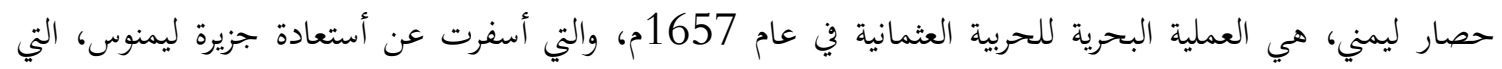

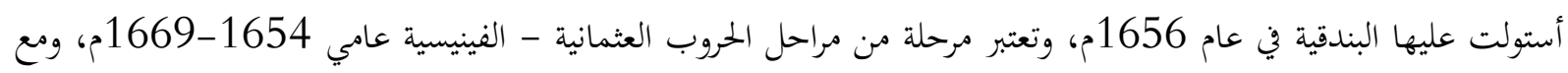

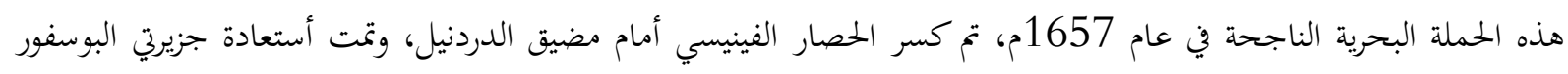

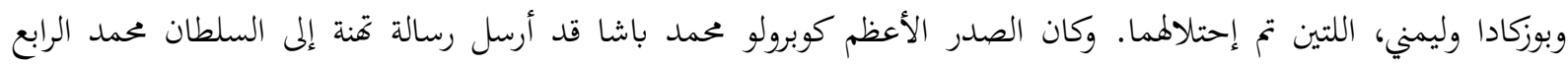

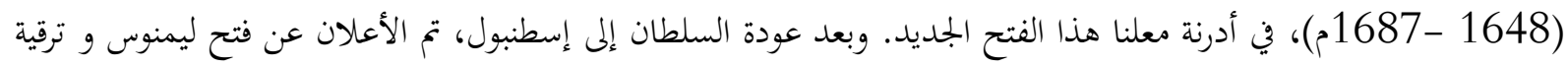

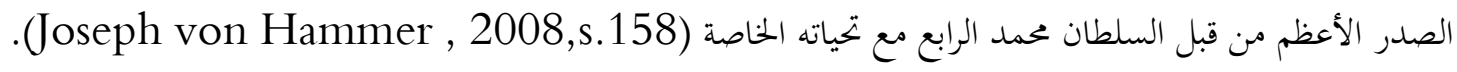

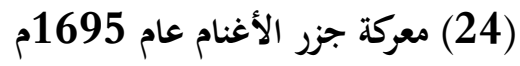

وقعت معركة جزر الأغنام للبحرية العثمانية بقيادة النقيب حسين باشا مع سفن البحرية لجمهورية البندقية بقيادة دريا

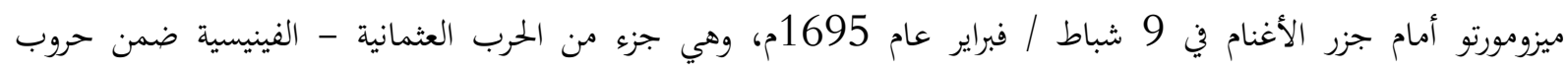

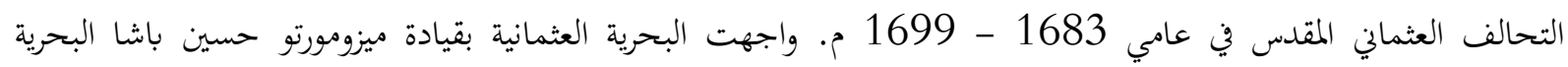

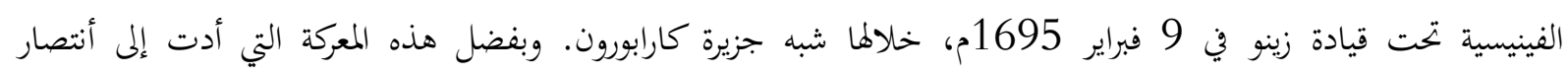

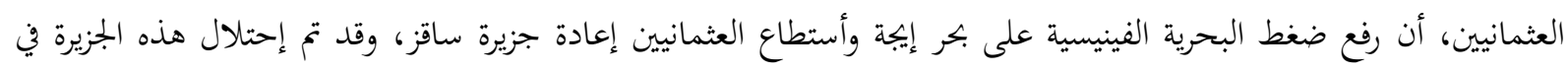

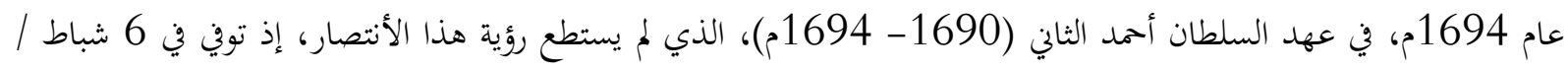
فبراير 1694م (Feridun Emecen , 2003, s. 191). 
الخور الثاني:

حروب البحرية العثمانية (1700-1918)

1) - (1) معركة إمروز البحرية الأولى عام 1717م

حدثت معركة إمروز بين البحرية العثمانية، التي كان لديها 44 سفينة حربية تحت قيادة كابتن دريا هوكا إبراهيم باشا،

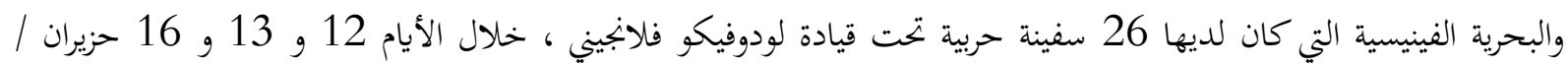

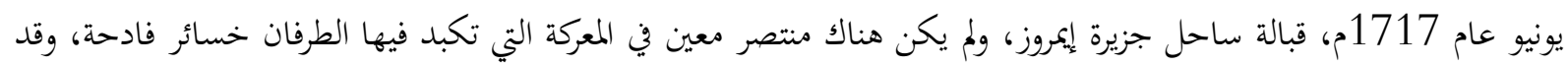

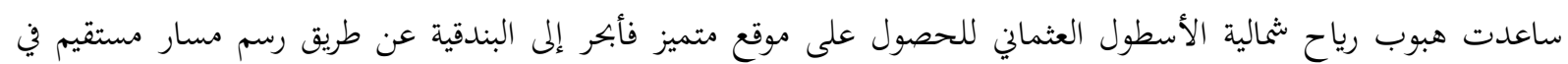
وقت مبكر حوالي الساعة الثالثة والنصف ليلاً، فهاجمت ثمانية سفن عثمانية السفن الفينيسية المسماة (كولومبا، تريونفو، سفينة

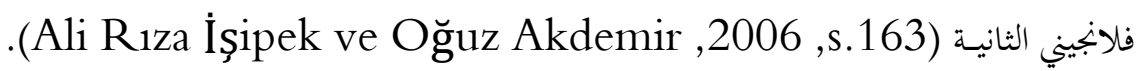
وفي يوم 13 حزيران / يونيو، التقى الاسطول الفينيسي مع الأسطول العثماني بالقرب من الطرف الغربي لجزيرة ليمنوس،

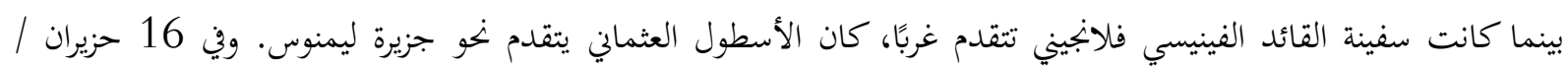

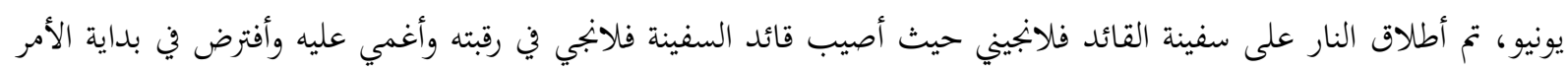
أنه قتل.

وفي تمام الساعة 15:30 أي بعد 5 ساعات من المعركة، أنسحب الأسطول العثماني بأتحاه جزيرة ليمني بستة سفن،

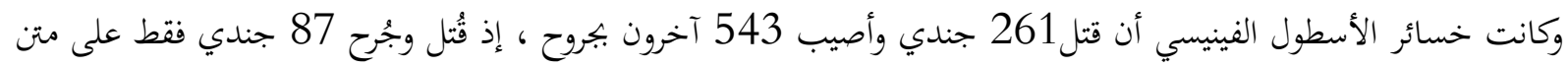

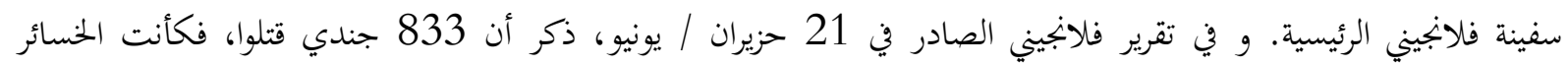

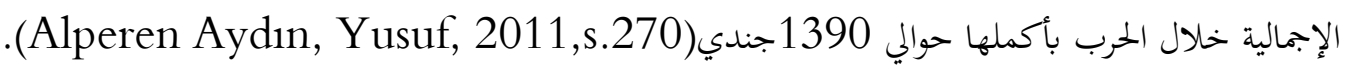

\section{(2) معركة لوري برنو عام 1737م.}

صباح يوم الجمعة المصادف 12 ربيع الثاني عام 1150 هـ، بينما كانت البحرية العثمانية في منطقة ديفيبوين، شوهد الأسطول الروسي المكون من 200 سفينة و خمسة قاذفات متجهه نخو بحر آزوف. عند ذلك تحركت البحرية العثمانية بأتحاه

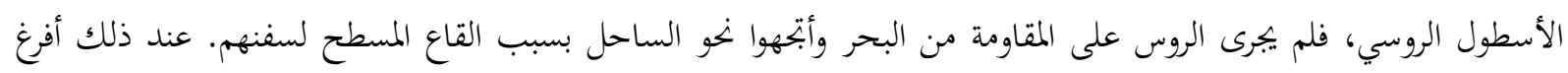

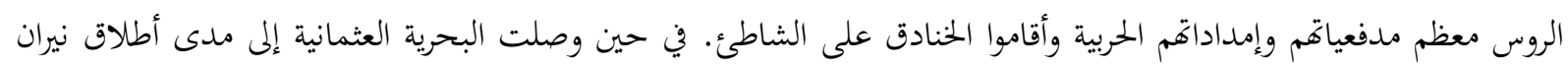

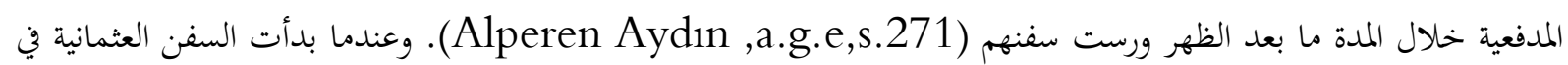
أطلاق نيران مدافعها، بدأ الروس في الرد على نيران سفنهم من الشاطئ. فكانت مدافع السفن العثمانية تضرب السفن الروسية

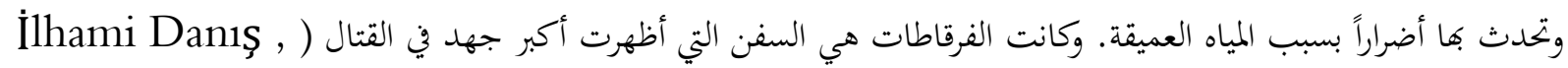
(2007, s. 72

\section{(3) معركة جشمة البحرية عام 1770م}

أندلعت معركة جشمة البحرية بين يومي 5-7 تموز / يوليو عام 1770م، بين البحرية الروسية والبحرية العثمانية مقابل

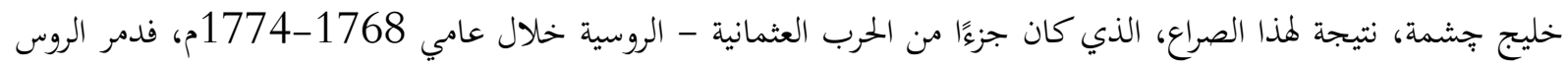

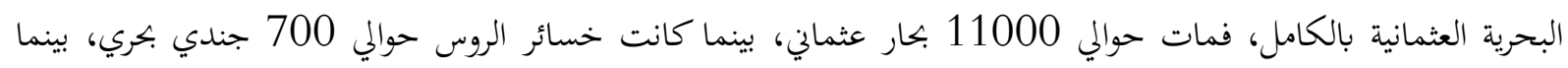
هرب الكابتن دريا ماندالزاده مع رئيسه النقيب حسام الدين باشا (Illhami Danış , 2007,s.72). 


\section{(4) - (4) - معركة كرج البحرية عام 1774م}

حدثت معركة مضيق كيرتش في جنوب كجز في شبه جزيرة القرم في يوم 20 حزيران / يونيو و يوم 9 متموز / يوليو عام

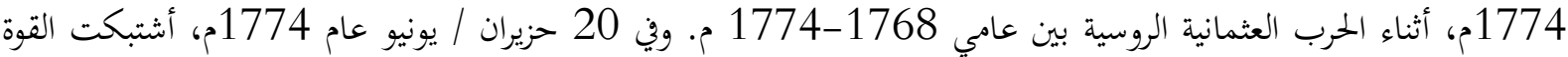

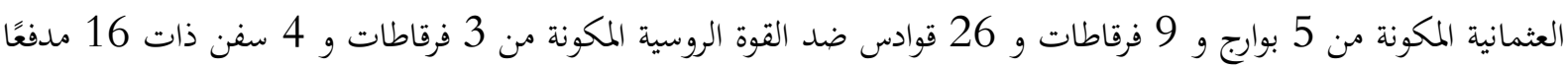

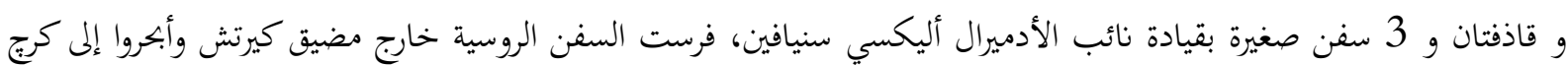

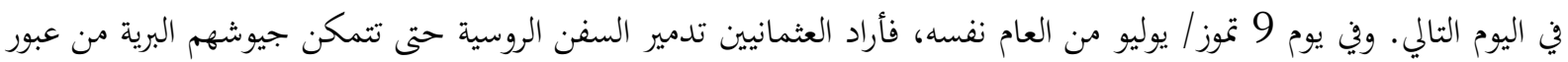

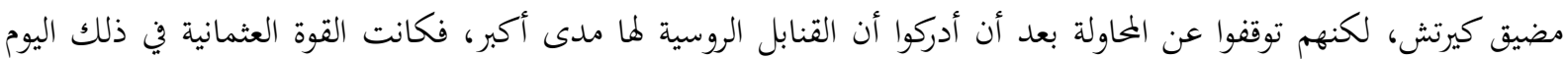

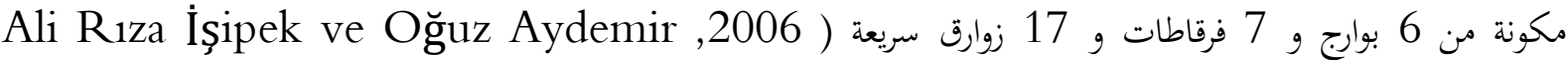

\section{(5) (5 ) حرب خليج ين قلعة 1787 - 1792م}

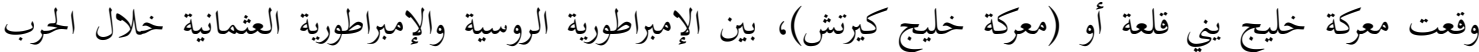

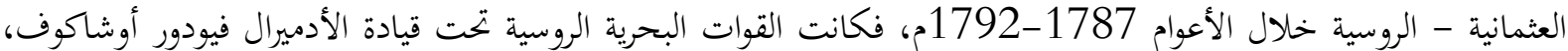

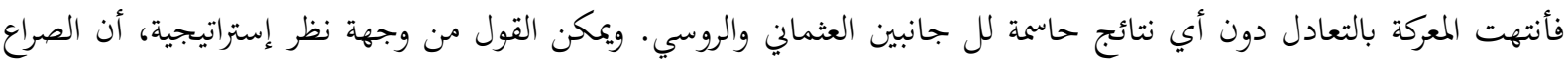

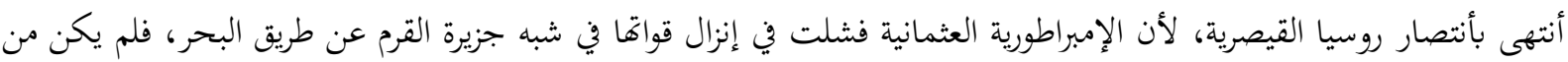
الممكن تدمير السفن الروسية نتيجة لذلك (R. C. Anderson , ,p.p 157).

\section{(6) - معركة ميناء طرابلس الأولى البحرية عام 1801 - 1805م}

سميت الحرب الطرابلسية نسبة إلى طرابلس (في لييا الحالية) أو الحرب البربرية الأمريكية الأولى (1801- 1805م)، و

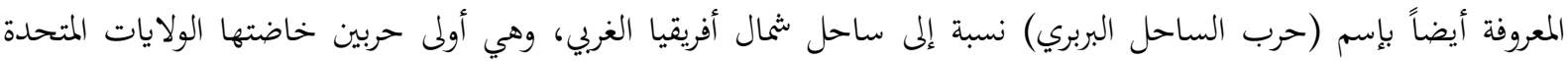

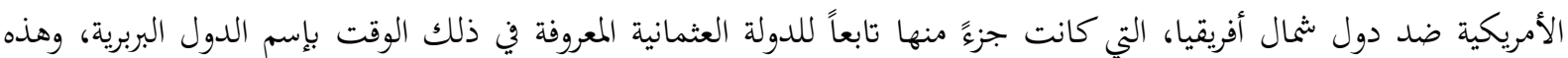

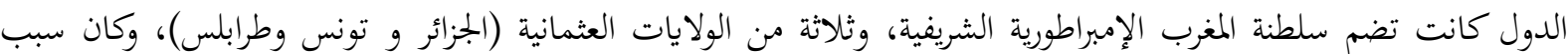

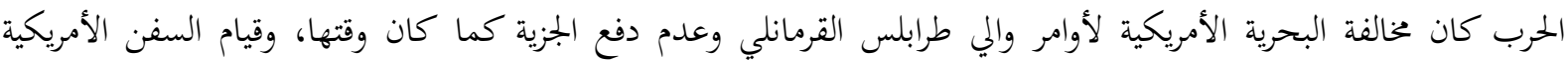

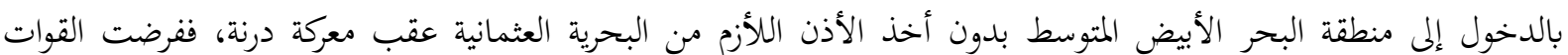

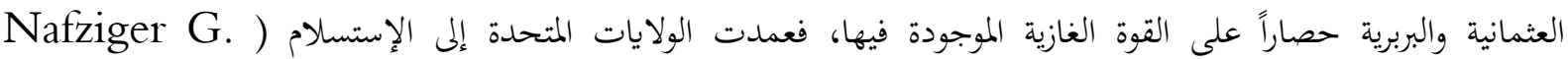

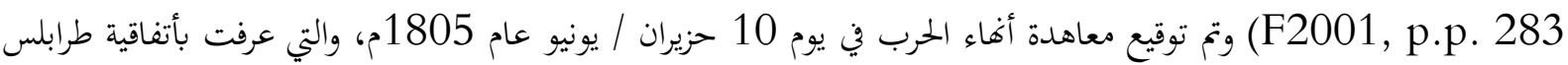
، وطلب باشا ليبيا يوسف باشا من الولايات المتحدة غرامات مالية تقدر بثلاثة ملايين دولار ذهباً، وضريبة سنوية قدرها

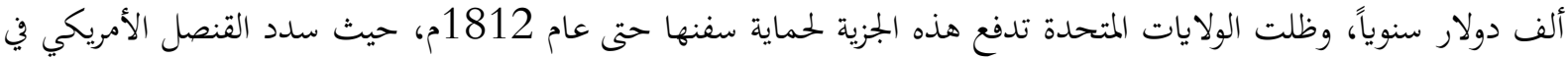
الدولة العثمانية 62 ألف دولار ذهباً، وكانت هذه هي المرة الأخيرة التي تسدد فيها الضريية السنوية والتي تسمى أحياناً (الحرب الحبائ

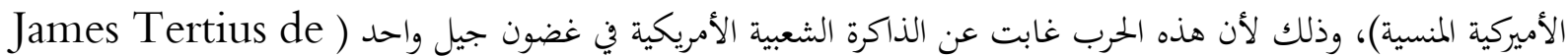
(Kay, 2004,p.p.253

\section{(7) الحرب البربرية الثانية عامي 1815 -1816م}

كانت الحرب البربرية الثانية حرباً بحرية بين الولايات المتحدة ودول شمال إفريقيا الأمازيغية التابعة للإمبراطورية العثمانية بين

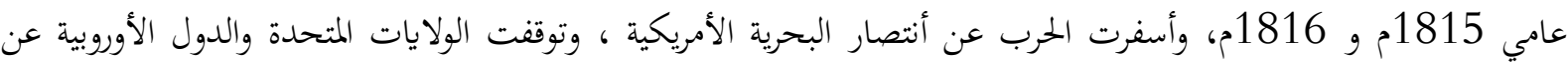

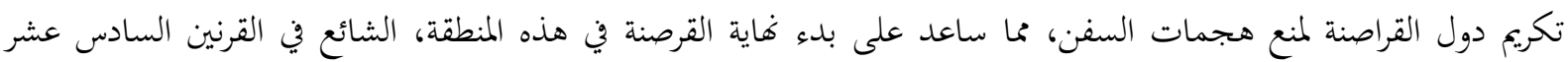


والثامن عشر للميلاد على مر السنين، فبدأت القوى الأوروبية في بناء سفن أكثر قوة فلم يستطع القراصنة البربريون مطابقتها في العدد أو التكنولوجيا (Wheelan, Joseph. 2003,p.p.232)

1827 (8) معركة ناوارين البحرية عام

وقعت معركة ناوارينو في يوم 20 تشرين الأول / أكتوبر عام 1827م، بين القوات البحرية العثمانية والمصرية ضد القوات البحرية البريطانية والفرنسية والروسية التي تعمل معاً، وتعرف هذه المعركة أيضاً بإسم (حادثة ناوارينو) أو (ناوارينو ريد) أو (كارثة

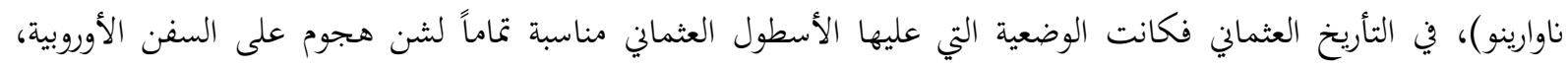

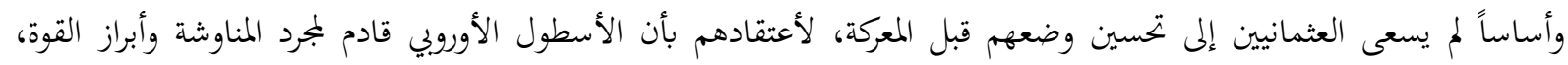

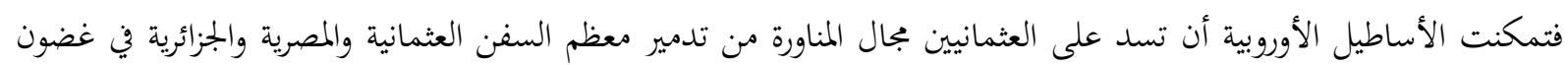
عدة ساعات ( Leiner, Frederic , 2007. s. 39-50)

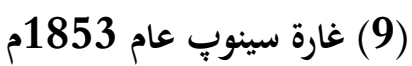

غارة سينوب (30 تشرين ثاني / نوفمبر عام1853م)، إحدى المعارك المهمة في حرب القرم، وفي هذه الغارة وجهت

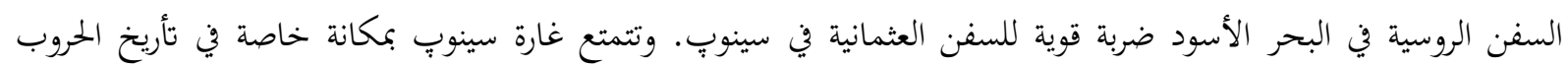

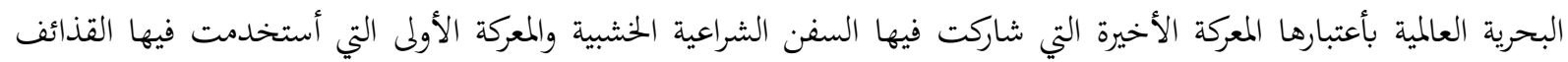

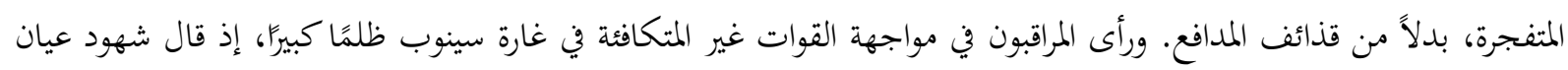

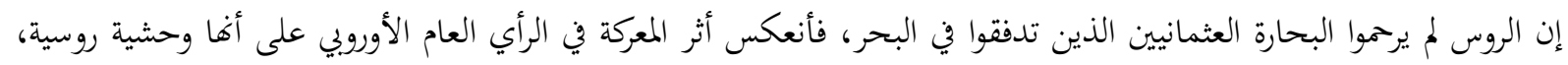

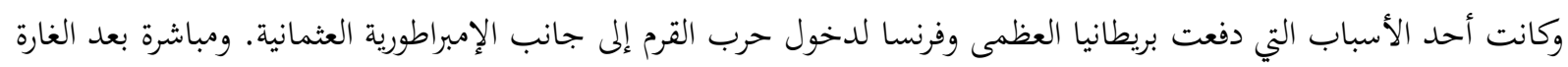

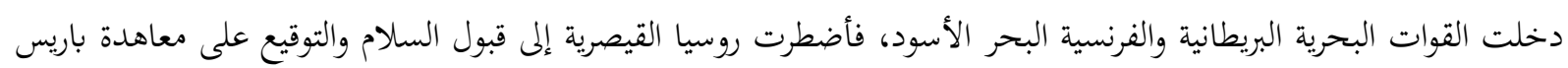
في 30 آذار / مارس عام1856م (W. James 1837, p.p. 89.).

\section{(10) حركة 93 الحربية عامي 1877-1878م}

وقعت حرب 93 أو الحرب العثمانية - الروسية عامي 1877-1878م في عهد السلطان العثماني عبد الحميد الثاني

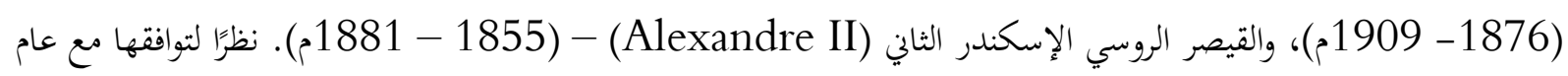

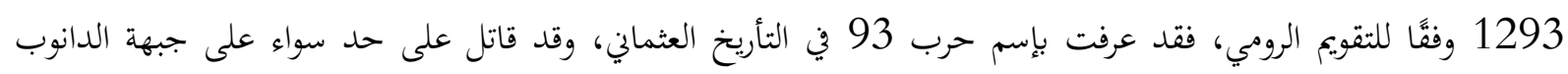

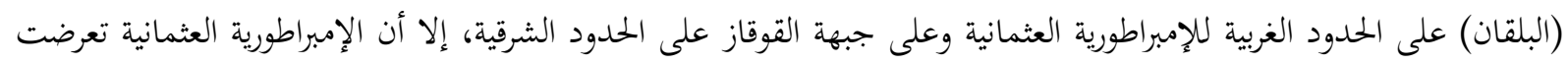

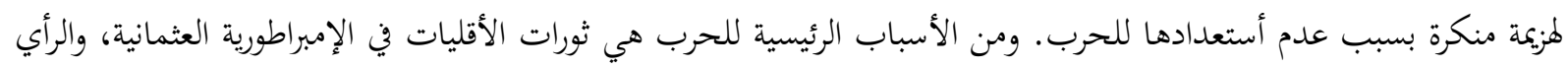

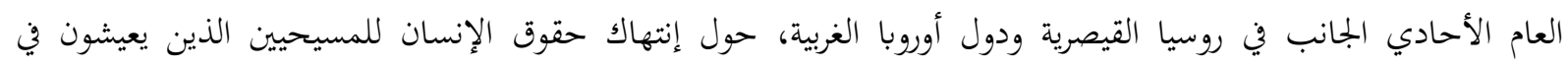

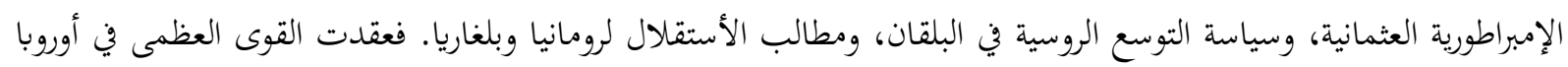

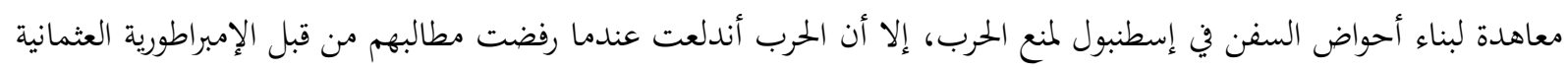

(Gulen, Nejat, 2001,s.225)

\section{(11) معركة إمروز البحرية الثانية عام1912م}

وقعت معركة إمروز أو معركة إيلي (سيدولاهير) خلال حرب البلقان الأولى في يوم 16 كانون الأول / ديسمبر عام

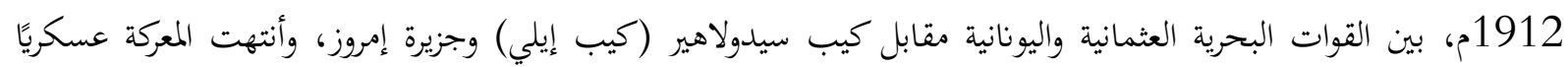

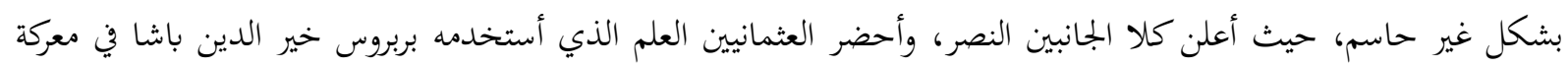
بريفيزا من المتحف البحري ورفعوه على سارية البارجة بربروس خير الدين (محمد فريد ، ص صلئ 587-647.)، بينما قدم اليونانيين 
عرضًا بحضور قائد البحرية في منطقة أفيروف و حافظ الإغريق على الوضع في شمال بحر إيجة لصالحهم، و لم تستطع البحرية

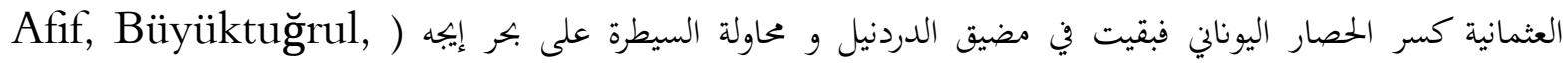
.(1974,s.175.

\section{(12) معركة موندروس البحرية عام 1913م}

وقعت معركة موندروس يوم 18 كانون الثاني / يناير عام1913م، بين الإمبراطورية العثمانية والقوات البحرية اليونانية،

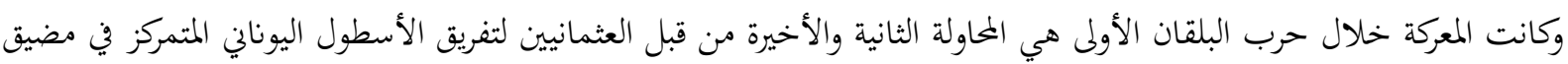

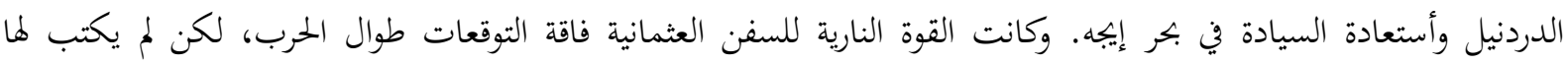
النجاح. ولم تتمكن سفينة أفيروف الروسية من تفادي نيران المدافع العثمانية، بينما تعرضت السفن العثمانية لاصابات باتهن بالغة نسبيًا،

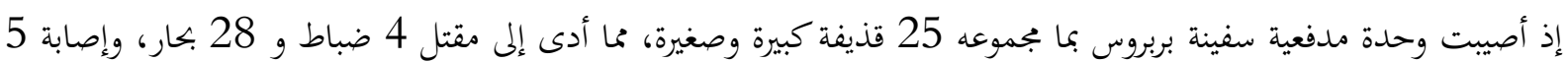

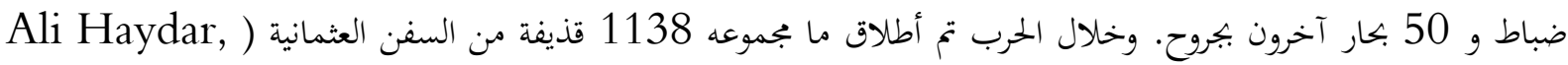

.(Emir, 1932,s.410.

\section{(13) حرب جاناق قلعة البحرية عام 1915م}

إن العمليات البحرية لحرب الدردنيل هي سلسلة من العمليات البحرية التي أجريت في مضيق الدردنيل في المدة من يوم 19 شباط / فبراير إلى يوم 18 آذار / مارس عام 1915م، بين أسطول الحلفاء الأوربيين والمدفعية البرية التابعة للإمبراطورية

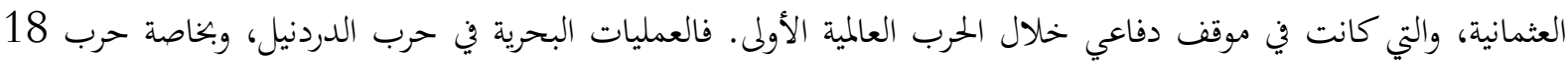

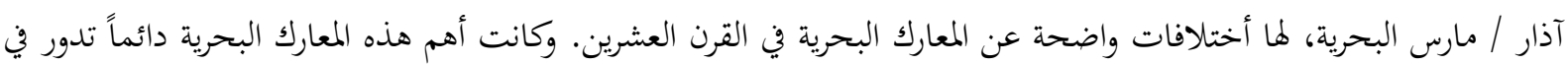
عرض البحر، ولم يتمكن أي مراقب من مراقبة ساحة المعركة بأكملها من موقعسه (

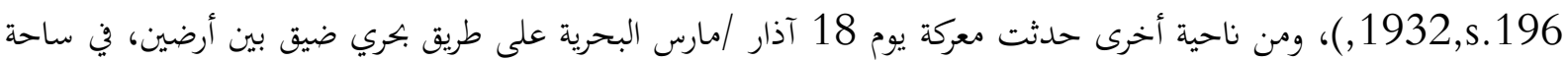

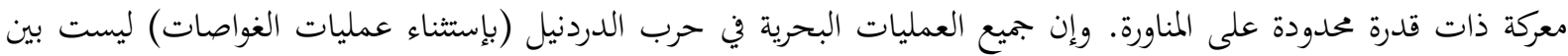

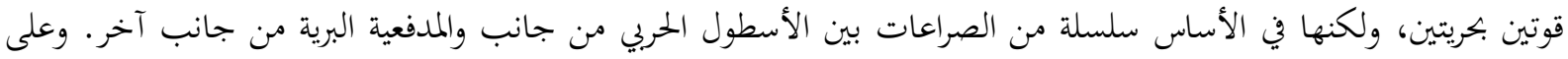

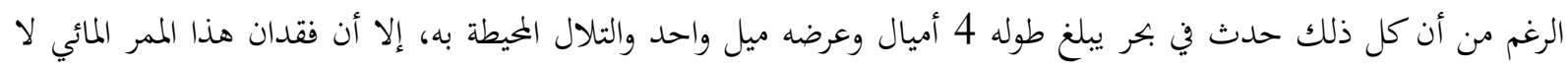
يعني خسارة معركة واحدة فحسب، بل خسارة الحرب بأكملها بالنسبة للإمبراطورية العثمانية ( بsarar Semiz

\section{(14) حرب إمروز البحرية الثالثة عام 1918م}

حدثت معركة إمروز في بحر إيجه في يوم 20 كانون الثاني / يناير عام 1918م، خلال الحرب العالمية الأولى. وحدث ذلك

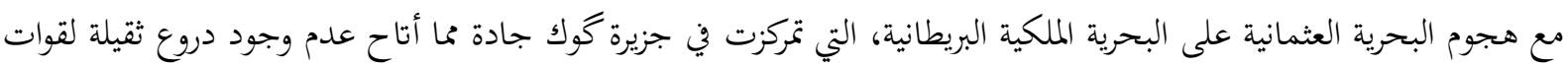
الحلفاء في هذه المنطقة، وهذا الأمر أعطى فرصة للطرادات القتالية العثمانية والتي كانت بإسم (يافوز و ميدلي الحفيف) لمهاجية

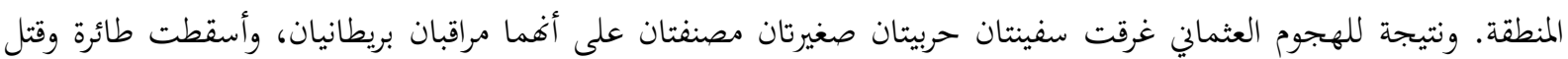
العديد من طاقمها(İbrahim Artuç , 2015,s.72) ، وكذلك ضربت السفن العثمانية التي لم تتعرض لأضرار كبيرة خلال المعركة، إلا أن الألغام البحرية التي زرعتها قوات الحلفاء لحماية الجزيرة من الهجمات العثمانية أثناء العودة. وقد تضرر الطراد

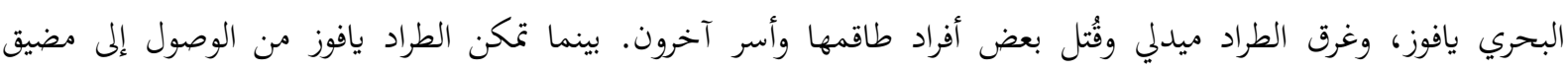

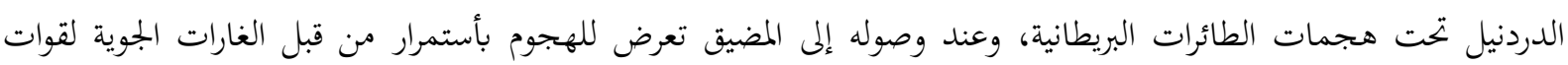


الحلفاء، حتى تم إنقاذه بعد ستة أيام. ونتيجة للضرر الذي لحق بأحدى السفينتين الحربيتين للإمبراطورية العثمانية وغرق الأخرى مماحدد بشدة التحركات المستقبلية للبحرية العثمانية (.Hüsamettin Sevengül, 1976,s.302.).

يلاحظ من خلال البحث فاعلية البحرية العثمانية، مع إن العثمانيين لم يتوقفوا أو يتأخروا في تحديث المنظومة الدفاعية

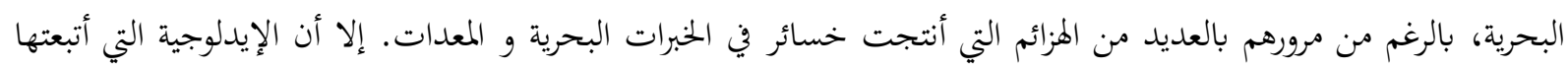

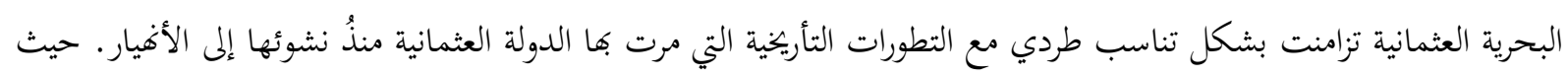

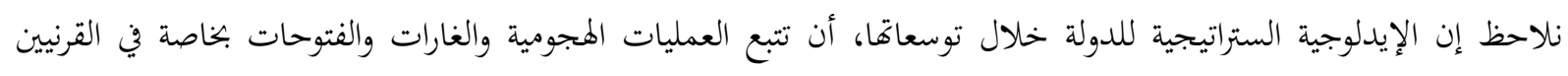
الخامس عشر والسادس عشر للميلاد، حيث تم فتح المناطق الواقعة على البحر مثل البصرة و مسقط و البندقية، غير إنه مع الركود

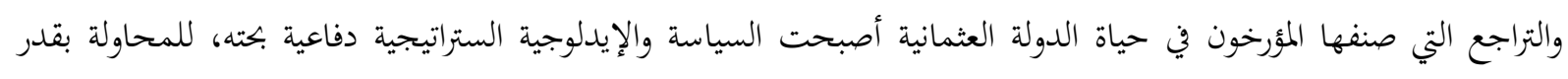

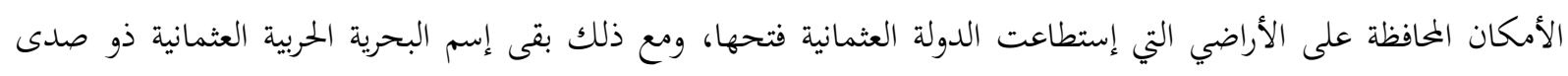

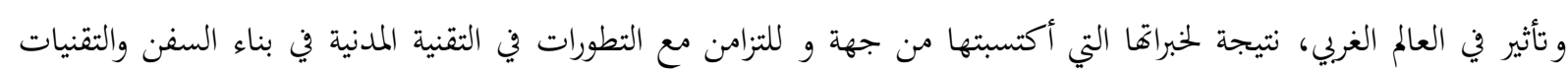
العسكرية البحرية التي حدثت من جهة أخرى أثر ظهور الثورة الصناعية في أوربا. 


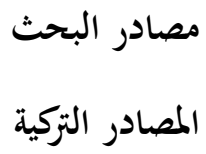

Abdurrahman Sağırlı, "Cezayir-i Irak-1 b veya Şatt-ül Arab'ın fethi , , İstanbul ,2000.

Abdülhakim Kılınç , Fuzulli’nin Kasidelerinde Basra Seferi , Türkiyat Mecmuası c.27/1 , Ankara, 2017.

Afif.Büyüktuğrlu,Osmanl Harp Tarihi, C.1, Deniz Basımevi, İstanbul.

Afif, Büyüktuğrul (1974). Osmanlı Deniz Harp Tarihi ,4. Cilt , Genelkurmay Başkanlığı Deniz Kuvvetleri Komutanlı̆̆

Ahmet C.Gazioğlu, Kıbrıs Türk Tarihi, Türk Dönemi 1570-1878, Lefkoşa; Kıbrıs Araştırma ve Yayın Merkezi, 1994, s.35-83.

Ahmet Güleryüz , Kadırgadan Kalyona Osmanlıda Yelken - Mikyas'ı Sefain , Denizler Kitabevi ,İstanbul , 2004.

Ahmet Kavas, Doğu Afrika Sahilinde Osmanlı Hakimiyeti:Kuzey Somali'de Zeyla İskelesinin Konumu, İslam Araştırmaları Dergisi (2001).

Aksaray, Y. Bülent, "Pîrî Reis'in Yaşamı, Yapıtları ve Bahriyesinden Seçmeler”, Pîrî Reis ,Araştırma Merkezi'nin yayını, Sayı: 7, İstanbul,2007.

Aktepe, M. Münir, İslam Ansiklopedisi ,Türkiye Diyanet Vakfi,Cilt:22, İstanbul 1994.

Ali Haydar, Emir, Balkan Harbinde Türk Filosu , Deniz Matabası , İstanbul ,1932,

Ali Rıza İşipek ve Oğuz Akdemir ,1770 Çeşme Deniz Savaşı,Denizler Kitabevi , İstanbul ,2006,s.163.

Ali Rıza İşipek ve Oğuz Aydemir , 1770Çeşme Deniz Savaşı,Denizler kitabevi , İstanbul ,2006.

Alperen Aydın, Yusuf, Sultanin Kalyonlari: Osmanlı donanmasinin yelkenli savas gemileri, 1701-1770, Küre Yayinlari, İstanbul ,2011,s.270.

Cezar, Mustafa, Mufassal Osmanlı Tarihi, Cilt II, Seher Matbaası, İstanbul,

Çevikel, Nuri Kıbrıs'ta Osmanlı Mirası (1570-1960), 47 Numara Yayıncılık, İstanbul 2006,

Dursun Bey, Tarih-i Ebû'l-feth,International Journal of Turkish Studies,1990.

Erhan Afyoncu, Osmanlı eşkıyayı inlerinde vurmuştu ,Sabah Gazetesi , Pazar, 20 Mart 2016.

Ertuğrul Önlap , Pîrî Reis'in Hürmüz Seferi ve İdamı Hakkındaki Türk ve Portekiz Tarihçilerinin Düşünceleri, Ankara Üniversitesi, Dil ve Tarih-Coğrafya Fakültesi , Ankara ,2000.

Feridun Emecen , ,"Limni", İslam Ansiklopedisi, Türkiye Diyanet Vakfi cilt: 27, İstanbul (2003). Gökhan Atmaca ve Doğan Tanriverdi, Türklerin Tarihinde 30 Büyük Deniz Savaşı, Denizler Kitabevi ,İstanbul ,2016.

Gulen, Nejat, Şanlı Bahriye: Türk Bahriyesinin İkiyüz Yıllık Tarihçesi 1773-1973, 2.baskı , Kastaş Yayınları , İstanbul, 2001.

Günen Çoşkun , Osmanlı Deniz Tarihinin Perveze - İnebahtı Döneminde Kaptanı Deryalık , Deniz Kuvvetleri Dergisi,Ankara, 1995 , s.562.

Halil. İnalcık ,Osmanlı İmpratorluğu Klasik çağı (1300-1600), YKY Yay, İstanbul 2004. 
Hüsamettin Sevengül, Birinci Dünya Harbinde Türk Harbi - Deniz Harekatı, 8. Genelkurmay Harp Tarihi Başkanlığı ,Ankara, 1976.

İbrahim Artuç, 1915 Çanakkale Savaşı, Kastaş Yayınları ,İstanbul ,2015.

İdris Bostan, Osmanlı Denizcilik Tarihi, İstanbulL Üniversitesi Açık ve Uzaktan Eğitimi Fakültesi Tarih Lisans Programı, İstanbul ,2000.

İdris Bostan ve Salih Özbaran, Başlangıçtan XV11 Yüzyılın Sonuna Kadar Denizcilik Tarihi , Deniz Yayınevi , İstanbul ,2009.

İlhami Danış , 1736-1739 Savaşlarında Kardeniz'de Osmanlı Donanması, Yayılmayan Yüksek Lisans Tezi, İstanbul Üniversitesi, 2007 ,s.72.

İsmail Hami, Danişmend, İzahlı Osmanlı tarihi kronolojisi , Türkiye Yayınevi , İstanbul ,1971. Joseph von Hammer, Hammer Büyük Osmanlı Tarihi , Üçdal Neşriyat, İstanbul , 2012.

Kavas, Ahmet, , İslam Ansiklopadisi , Türkiye Düyanet Vakfi ,Ankara ,2005,

Kenneth Meyer Setton , 1204-1571: The thirteenth and fourteenth centuries , American Philosophical Society, 1976

Levent Tonyalı ve Gökhan Atamaca, Türk Deniz Harp Tarihi Atlası, Deniz Kuvvettleri Komutanlı̆̆1 Yayınevi, İstanbul, 2010.

Luigi Tommaso Belgrano, Documenti Riguardanti La Colonia Genovese Di Pera ,. Behçet Gücer tercümesi, , Türk Tarih Kurumu Kütüphanesi , Ankara ,1990.

Mahmut Ak, Seydi Ali Reis, İslam Ansiklopedisi , Türkiye Düyanet Vakfi ,Ankara ,2019

Mehmet Kiremit, Mir'atü'l-Memalik (Seydi Ali Reis) ,TDK Yayınları ,Ankara, 1999.

Nejat Tarakçı, Deniz Gücünün Osmanlı Tarihi Üzerindeki Etkileri ,Deniz Basımevi Müdürlüğ̈̈ ,İstANBUL ,2009.

Refik Özdek, Türklerin Altın Kitabı, Tercüman Yayınevi , İstanbul ,2010.

Refik Özdek, Türkler'in Altın Kitabı Cilt-3: Tercüman Yayınevi. İstanbul,1990.

Uzunçarşılı, İsmail Hakkı, Büyük Osmanlı Tarihi, 7. Baskı, II. Cilt,TTK Yayınları ,Ankara, 1988.

Yaşar Semiz 18 Mart 1915 Çanakkale Deniz Savaş1: Sebepleri, Gelişimi ve Sonuçları , S.Ü.Türkiyat Araştırmaları Enstitüsünün Araştırma degisi, Sakarya ,2000.

Yusuf Halaçoğlu , İslam Ansiklopadisi , Türkiye Düyanet Vakfi , 5. Cilit.ankara,1995.

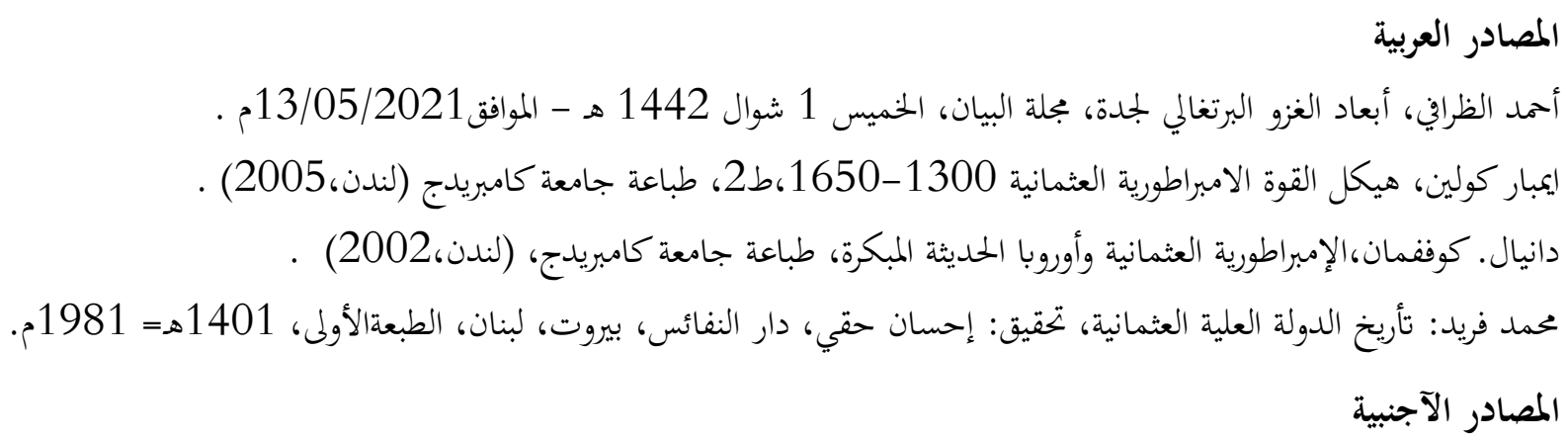

Clifford Edmund Bosworth, Historic Cities of the Islamic World, 2007

James Tertius de Kay, A Rage for Glory: The Life of Commodore Stephen Decatur, USN. Free Press, 2004. 
Leiner, Frederic C. (2007). The End of Barbary Terror, America's 1815 War against the Pirates of North Africa. Oxford University Press, 2007.

Lyle N. McAlister, Spain and Portugal in the New World, 1492-1700, Cilt 3 , Univ of Minnesota $\operatorname{Pr}(1984)$.

Nafziger G. F. Historical Dictionary of the Napoleonic Era. Scarecrow Press. 2001.

Norris, John J. , A History of Venice Penguin, Londra , 1977 ,

R. C. Anderson, Naval Wars in the Levant 1559-1853, Princeton University Press ,2010.

Rogers, Clifford J. Readings on the Military Transformation of Early Modern Europe, San Francisco: Westview Press, 1995.

W. James, Naval History of Great Britain, Cilt VI, (London, 1837).

Wheelan, Joseph. Jefferson's War: America's First War on Terror, 1801-1805. New York: Carroll \& Graf, 2003.

Zaka HannaKour, The History of Aden , Taylor \& Francis Compeny , Erişim,2012. 